\title{
Statistical adaptation of ALADIN RCM outputs over the French Alps - application to future climate and snow cover
}

\author{
M. Rousselot, Y. Durand, G. Giraud, L. Mérindol , I. Dombrowski-Etchevers, M. Déqué, and H. Castebrunet \\ Météo-France/CNRS, CNRM-GAME URA1357, Grenoble, France \\ Correspondence to: M. Rousselot (marie.rousselot@gmail.com)
}

Received: 6 December 2011 - Published in The Cryosphere Discuss.: 19 January 2012

Revised: 4 June 2012 - Accepted: 15 June 2012 - Published: 24 July 2012

\begin{abstract}
In this study, snowpack scenarios are modelled across the French Alps using dynamically downscaled variables from the ALADIN Regional Climate Model (RCM) for the control period (1961-1990) and three emission scenarios (SRES B1, A1B and A2) for the mid- and late 21st century (2021-2050 and 2071-2100). These variables are statistically adapted to the different elevations, aspects and slopes of the Alpine massifs. For this purpose, we use a simple analogue criterion with ERA40 series as well as an existing detailed climatology of the French Alps (Durand et al., 2009a) that provides complete meteorological fields from the SAFRAN analysis model. The resulting scenarios of precipitation, temperature, wind, cloudiness, longwave and shortwave radiation, and humidity are used to run the physical snow model CROCUS and simulate snowpack evolution over the massifs studied. The seasonal and regional characteristics of the simulated climate and snow cover changes are explored, as is the influence of the scenarios on these changes. Preliminary results suggest that the snow water equivalent (SWE) of the snowpack will decrease dramatically in the next century, especially in the Southern and Extreme Southern parts of the Alps. This decrease seems to result primarily from a general warming throughout the year, and possibly a deficit of precipitation in the autumn. The magnitude of the snow cover decline follows a marked altitudinal gradient, with the highest altitudes being less exposed to climate change. Scenario A2, with its high concentrations of greenhouse gases, results in a SWE reduction roughly twice as large as in the low-emission scenario B1 by the end of the century. This study needs to be completed using simulations from other RCMs, since a multi-model approach is essential for uncertainty analysis.
\end{abstract}

\section{Introduction}

Mountains are a key component of the global ecosystem and biodiversity, presenting major sources of water as well as minerals, forests, and agricultural products. They also represent areas of interest for the detection of climate change and the assessment of climate-related impacts (Beniston, 2003). In the Alps, snow is a natural water storage component, an important hydropower factor and a major source of income for the tourist industry. Thus, snow cover reduction is likely to have important environmental and socio-economic impacts on water resources, winter tourism, ecology and local changes in climate through potential feedbacks on, for instance, surface temperature and snow albedo. In a context of global warming, an essential prerequisite is thus to understand the links between climate and snow cover for present and future periods.

Long-term snow cover climatologies have been established for about the last half of the 20th century throughout the Alps on the basis of observations or reanalyses for Switzerland (Laternser and Schneebeli, 2003), France (Martin and Etchevers, 2005; Durand et al., 2009a,b), Austria (Hantel et al., 2000; Schöner et al., 2000) and Italy (Acquaotta et al., 2009). These studies suggest that, since the early 1980s, snow cover has been substantially and rapidly reduced in most of the low and mid-altitude areas. Simultaneously, temperatures have largely increased, up to $2^{\circ} \mathrm{C}$ since 1900 at high elevations and at a rate often much faster (about 3 times) than on the global scale (Schöner et al., 2000; Beniston et al., 2003; Durand et al., 2009a). In contrast, evidence for precipitation trends is not clear, showing either a slight increase in winter and a decline in summer, as in the Swiss 
Alps (Frei and Schär, 1998; Beniston et al., 2003), or no significant trend, as in the French Alps (Durand et al., 2009a).

Concerning future snow evolution, first estimations have been obtained through simple extrapolations of current observed trends (e.g. Beniston et al., 2003) or simple sensitivity studies with snow models (Martin et al., 1994; Laternser and Schneebeli, 2003). Other attempts have been made to obtain more detailed scenarios of snow cover derived from physically-coherent climate scenarios (Martin et al., 1997). However, the main obstacle to many climate impact studies, in particular future snow cover modelling, is strongly related to the difficulty of modelling climate at relevant spatial scales. Most of the 21 st century climate projections made in recent years have relied on climate scenarios from global climate models (GCMs). However, the typical scale of these models $(150-300 \mathrm{~km})$ is very insufficient for most impact studies, particularly when working in mountain areas where a much higher resolution is required to properly resolve the topography. Therefore, so-called downscaling techniques, often categorized into statistical and dynamical approaches, have been developed. We present these approaches briefly here, which are reviewed in, e.g. Maraun et al. (2010b).

In the first downscaling approach, statistical links are determined between large-scale climate predictors (from observations or climate models) and local observations of the variable of interest (e.g. temperature, precipitation). There is a broad range of statistical methods of contrasting complexity, from simple regression and analogue methods to more complex weather typing and neural network approaches, together with their combinations (see review by, e.g. Maraun et al., $2010 \mathrm{~b})$. Their common point is that they all rely on the availability and quality of observation series, which may pose problems in some mountain regions. They are also based on the hypothesis that the statistical link existing between the spatial scales in the current climate will remain valid for future changed climatic conditions. Despite these limitations, statistical methods have been extensively used in the Alps to work on specific months (Frey-Buness et al., 1995), reconstruct recent temperature evolution (Kettle and Thompson, 2004), obtain precipitation scenarios (Schmidli et al., 2007) or study snow cover (Martin et al., 1997).

In contrast, dynamical downscaling explores the physical links between large and fine-scale atmospheric features, often by running regional climate models (RCMs) nested into GCMs. RCMs can be run at fine resolution (e.g. $2 \mathrm{~km}$ for the Alps, Hohenegger et al., 2008) but, because of their high computational costs, such simulations can only cover short time periods (hours to weeks). Longer climatic simulations (typically $30 \mathrm{yr}$ ) are usually run at $25-50 \mathrm{~km}$ resolution (see European projects such as FP5-PRUDENCE (Christensen and Christensen, 2007), FP6-ENSEMBLES (Hewitt and Griggs, 2004; van der Linden and Mitchell, 2009)), or on a smaller domain at $10-15 \mathrm{~km}$ resolution (FP6-CECILIA (Farda et al., 2010) and CLAVIER (Hagemann et al., 2004). Recently, other climatic simulations have been conducted over Europe at a spatial scale of $10 \mathrm{~km}$ (Déqué and Somot, 2008). All these studies reveal that increased model resolution generally improves the representation of the topography, the physical processes and the subgrid parametrization, and thus the RCM skill to reproduce the observed climate.

In an ongoing project, SCAMPEI (French ANR project, 2009-2011), regional climate models are run at $\sim 10 \mathrm{~km}$ resolution to specifically study mountain climate and its impacts on the evolution of snow cover and debris flows in France. In this framework, our objective is to obtain climate scenarios adapted to detailed snow cover modelling, i.e. describing the physical evolution of the snow properties according to massif, altitude and exposure. To this aim, we adopted a combined statistical-dynamical approach, in which some of these simulations were statistically associated with analysis of real observed meteorological situations in the French Alps. For the specific snow application of the study, we also ran a physical snow model. Results on climate and snow cover evolution are presented for the end of the 20th century and the periods 2021-2050 and 2071-2100, as well as for various IPCC greenhouse gas (GHG) emissions hypotheses.

The paper is organized as follows. In the next section, we describe the numerical set-up. Validation of the downscaling method and results of the simulated changes in climate and snow cover are presented in Sects. 3 and 4 respectively. These results are subsequently discussed in Sect. 5, which is followed by a general conclusion and recommendations for future research.

\section{Numerical setup}

In this study, we performed a simple analogue search over the French Alps to obtain climate series suitable for snow modelling. The analogue method uses fine-scale outputs of the ALADIN RCM and fine-scale meteorological analysis. Several experiments were carried out to validate the method and obtain future climate scenarios.

\subsection{ALADIN outputs}

ALADIN is a French RCM that was initially designed in the early 1990s as a limited area model derived from the global spectral model ARPEGE/IFS for short-range forecasting (Bubnová et al., 1995). A climate version of the model, based on the same physical parametrization as ARPEGE (Radu et al., 2008), has been validated at 50 and $25 \mathrm{~km}$ resolution on a domain covering Europe in the framework of the EU-FP6 projects ENSEMBLES and CECILIA. Recent works over Europe indicate that $12 \mathrm{~km}$ resolution greatly improves the fields simulated by ALADIN (Déqué and Somot, 2008; Colin et al., 2010).

Here, in the framework of the SCAMPEI project, we use outputs of several recent 30-yr ALADIN simulations run at a $12 \mathrm{~km}$ resolution over France. These runs cover a reference 


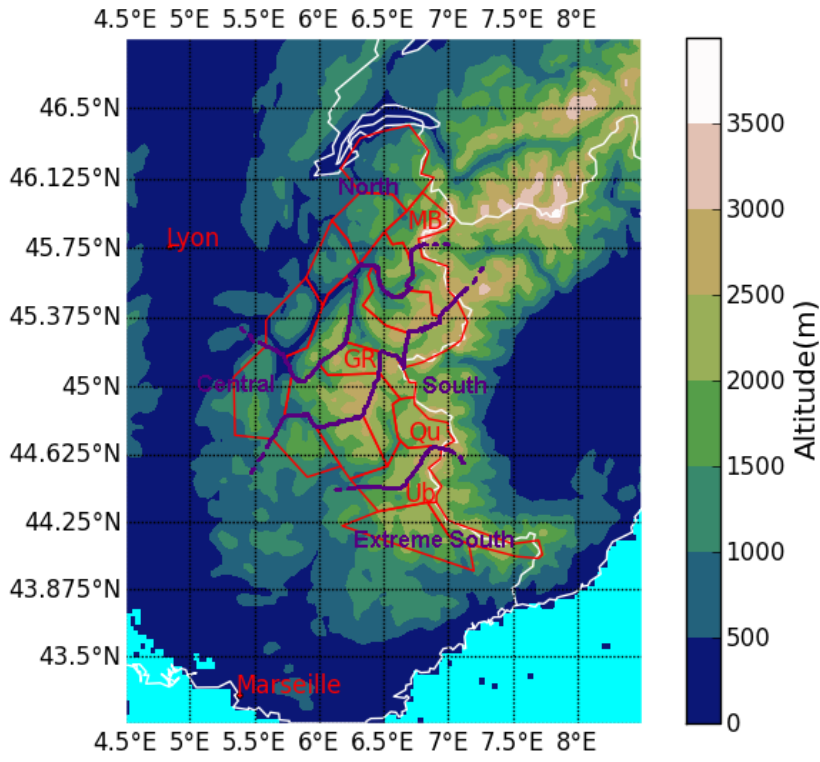

Fig. 1. Map showing surface elevation of the ALADIN RCM subdomain considered in this study. The analog research between the extended ERA-40 and ALADIN fields, interpolated on the analysis grid (black dots), was performed over the whole domain. Snow modelling was conducted on the 23 massifs of the French Alps as defined in SAFRAN (red line, see text for details). MB, GR, Qu and Ub designate the Mont-Blanc, Grandes Rousses, Queyras and Ubaye massifs respectively. The four Alpine sub-domains, North, Central, Southern and extreme Southern Alps, are identified.

period (1961-1990) and two periods of the 21 st century (2021-2050 and 2071-2100), under different hypotheses of economic development and GHG emissions (IPCC scenarios $\mathrm{A} 1 \mathrm{~B}, \mathrm{~A} 2$ and $\mathrm{B} 1$ ). The driving simulations are the same as in the FP6-CECILIA project: they consist of global ARPEGE simulations with variable resolution $(50 \mathrm{~km}$ over France) driven by sea surface temperatures (SST) from the IPCCAR4 contribution (Gibelin and Déqué, 2003).

\subsection{Analogue method and snow modelling}

A simple analogue method was applied on a domain centred on the French Alps and snow modelling was carried out on the Alpine sub-domain (Fig. 1). Briefly, the modelling set-up, which is sketched in Fig. 2, was as follows:

- ALADIN atmospheric fields of air temperature at $2 \mathrm{~m}$ above ground $(\mathrm{T} 2 \mathrm{~m})$ and $500 \mathrm{hPa}$ geopotential height (Z500), available with a 6-h time step, were linked through a statistical distance to real, analogous largescale reanalyses.

- The reanalyses were available from Durand et al. (2009a), referred to as D09a below, who used them to force SAFRAN and establish a fine-scale climatology on the French Alps. The reanalyses consisted of a combination of ERA-40 fields from 1958-2002

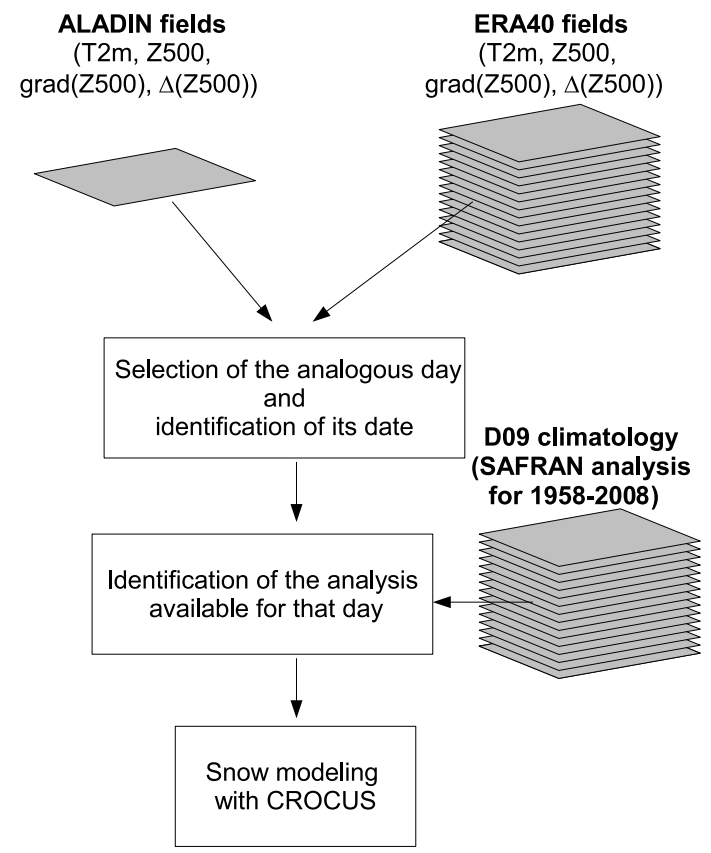

Fig. 2. Schematic diagram of the method, from analogues selection to snow modelling.

(ECMWF, 2004) and Météo-France's ARPEGE analysis from 2003-2008. These fields, initially produced at $\sim 125 \mathrm{~km}\left(1.125^{\circ}\right)$ and $\sim 50 \mathrm{~km}$ resolution respectively, were adapted by D09a with scale appropriate procedures on a grid of $\sim 35 \mathrm{~km}$ resolution (Fig. 1). This grid corresponds roughly to the spatial scale of the massifs considered by Météo-France for snow modelling. In the present work, these atmospheric fields were used at the same resolution and referred to as "extended ERA40 fields".

- As our final goal is to simulate snow cover at the scale of the massif and produce monthly or annual diagnostics, the $12 \mathrm{~km}$-ALADIN fields were interpolated on the same grid (Fig. 1). Thus, details at a scale finer than the scale representative of the snow modelling outputs were not considered. As a consequence, the analogues that were sought each day for all the Alpine massifs were representative of the main features of the meteorological flow over the Alps at a spatial resolution compatible to the size of the massifs.

- The date series of these analogues was then used to retrieve finer real meteorological fields from the D09a climatology. This climatology consists of weather reanalyses for 1958-2008, defined at the massif-scale for elevations ranging from $900-3600 \mathrm{~m}$ a.s.l. and considering various orientations and slopes. It provides hourly fields of air temperature, quantity and phase of precipitation, humidity, cloudiness, horizontal wind speed, and direct and indirect solar radiation (D09a). 
Thus, in this method, raw, large-scale fields from the ERA40 database are not used explicitly for snow modelling.

The statistical distance, or analogue criterion, is built as follows. For each field $X$, unbiased seasonal anomalies $\widetilde{X}$ and seasonal standard deviation $\sigma$ are computed at each grid point $i$ on the 1961-1990, 2021-2050 and 2071-2100 periods for the ALADIN dataset and on the 1958-2008 period for the extended ERA40 dataset. Seasonal means and variances used to statistically center ERA40 variables are steady during the research and correspond to the ALADIN field season. A Mahalanobis distance $d$ (Mahalanobis, 1936) is then computed over the whole domain every 6 hours following

$d=\sqrt{\sum_{i=1}^{N} \frac{\left[\tilde{X}_{\mathrm{ala}}(i)-\tilde{X}_{\mathrm{era}}(i)\right]^{2}}{\sigma_{\mathrm{ala}}(i) \sigma_{\mathrm{era}}(i)}}$,

where the subscripts ala and era refer to ALADIN and ERA40 fields, respectively, and $N$ is the number of grid points. In this computation, there is no formal constraint in terms of date or season in the analogue research: for a given day of ALADIN, any extended ERA40 dates, from July 1958 to December 2008, can be selected. Nevertheless, in practice extended ERA40 days out of the season are penalized as they result in larger ERA40 deviations $\widetilde{X}_{\text {era }}(i)$.

Daily distances (from 06:00 UTC to 06:00 UTC the next day) are calculated on the near-surface field $\mathrm{T} 2 \mathrm{~m}$ and the following upper-air fields: Z500, Z500 horizontal gradient (defined by its zonal and meridional components) and Z500 second spatial derivative. The analogue is determined by minimizing the sum of these distances. To account for the different topographies underlying the ALADIN and ERA40 fields, guarantee temporal coherence in the seasonal insolation and thus reproduce the main features of the current climate as well as possible, the analogue fields are corrected a posteriori by a quantile-quantile method (Déqué, 2007, see also Sect. 3) and appropriate factors.

Finally, these SAFRAN fields are used to force the CROCUS snow model (Brun et al., 1989, 1992), which computes profiles of temperature, density, liquid-water content and crystal types within the snowpack for the same elevations and orientations as those in SAFRAN and for three slopes (flat, $20^{\circ}$ and $40^{\circ}$ ). These runs thus describe the snowpack evolution on the French Alpine massifs (Fig.1). This approach is similar to that of Durand et al. (2009b) (referred to as D09b hereafter), where a snow climatology is derived for 1958-2002 using D09a SAFRAN data in the forcing of CROCUS, the difference being that climate series derived from ALADIN, instead of ERA 40, are treated here.

\subsection{Experiments}

A first set of experiments, which included a control (CT) and a cross (CR) experiment, were performed to test the method on present day climatology (Table 1). The CT experiment was run using the ALADIN outputs for 1961-1990. In this
Table 1. Origin of $\mathrm{T} 2 \mathrm{~m}$ and $\mathrm{Z} 500$ datasets used for the analogue search in the CT and CR experiments.

\begin{tabular}{lcl}
\hline CT & ALADIN & ERA40 \\
CR & ERA40 & ERA40 \\
\hline
\end{tabular}

experiment, the resulting simulated climate may differ from the D09a one, used as a reference, either because the ALADIN predictors differ from real observed situations or because the analogues search method itself introduces some errors. To specifically verify the method, the cross experiment (CR) was run, in which the set of predictors exactly matched the large-scale features of the D09a dataset. Thus in CR, the analogue method was applied between the extended 19582008 ERA40 fields and the same dataset from which a moving 20-day window centred on the day of interest had been removed to avoid the selection of an analogue belonging to the same meteorological situation. Given the large size of the extended ERA40 subset ( 14000 days), it can be assumed that the mean value and variability tend to be identical for all datasets. In this set-up, a perfect analogue method would thus provide the same climatology as in the D09a study. The results of the experiments are described in the validation section (Sect. 3).

Future climate was studied through a second set of 6 experiments, corresponding to the 3 IPCC emission scenarios treated by ALADIN (IPCC, 2007) for each of the periods 2021-2050 and 2071-2100:

- the A1B scenario, which describes a future world with rapid, globalized future economic growth, the development of new, more efficient technologies, and a global population increase until mid-century with decline thereafter.

- the A2 scenario, which assumes regionally heterogeneous economic and technological development throughout the world and a continuously increasing population. This is one of the most GHG emissive IPCC scenarios.

- the B1 scenario, which assumes similar evolution of the global population to that in $\mathrm{A} 1 \mathrm{~B}$, but with an economy dominated by services and information activities and the use of clean technologies. This scenario is the least emissive one, with GHG emissions that are stabilized before the end of the century.

The results of these experiments are presented in Sect. 4.

\section{Validation on the control period}

\subsection{Weather types}

In its analysis scheme, SAFRAN is based on a classification of the input meteorological large-scale fields into 7 weather 


\begin{tabular}{|l|l|l|l|}
\hline Type & Pressure fields & $\begin{array}{l}\text { Syn. } \\
\text { flows }\end{array}$ & $\begin{array}{l}\text { Precipitation } \\
\text { on the Alps }\end{array}$ \\
\hline 1 & Low, flat gradient over France & Sor N & $\begin{array}{l}\text { Light- } \\
\text { moderate }\end{array}$ \\
\hline 2 & Low, on the Northem Alps & SW & $\begin{array}{l}\text { Light- } \\
\text { heavy }\end{array}$ \\
\hline 3 & $\begin{array}{l}\text { Through along a } \\
\text { Slovaquia/Baltic sea axis }\end{array}$ & N-NW & $\begin{array}{l}\text { Light- } \\
\text { heavy }\end{array}$ \\
\hline 4 & Low, on Scotland and Sweden & W-NW & Heavy \\
\hline 5 & $\begin{array}{l}\text { High on the Alps, low } \\
\text { gradients }\end{array}$ & SW & $\begin{array}{l}\text { None- } \\
\text { moderate }\end{array}$ \\
\hline 6 & $\begin{array}{l}\text { Low, through long a } \\
\text { Italia/Scandinavia axis }\end{array}$ & Sor N & $\begin{array}{l}\text { Light- } \\
\text { moderate }\end{array}$ \\
\hline 7 & High and stable & Weak & None - light \\
\hline
\end{tabular}
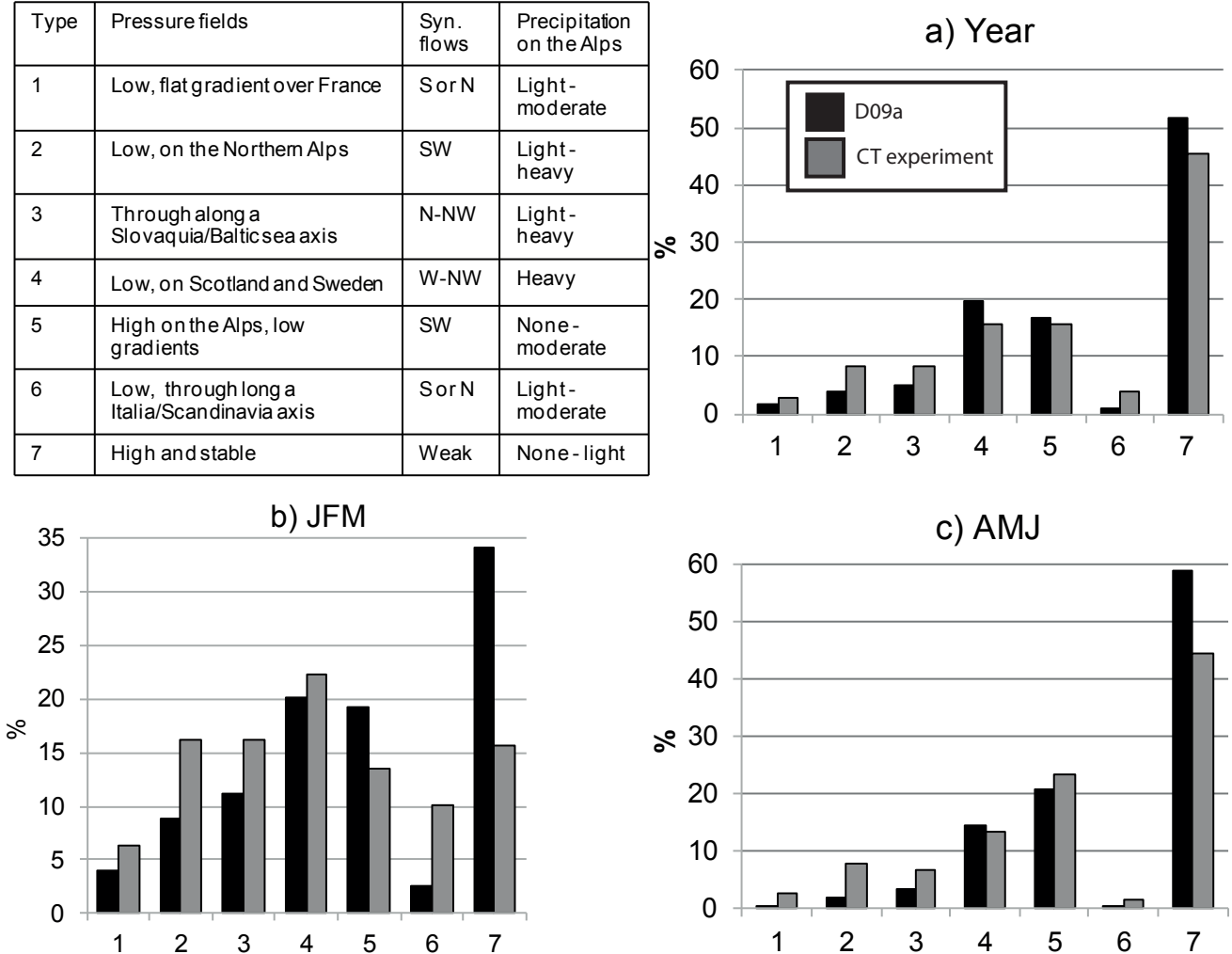

d) JAS

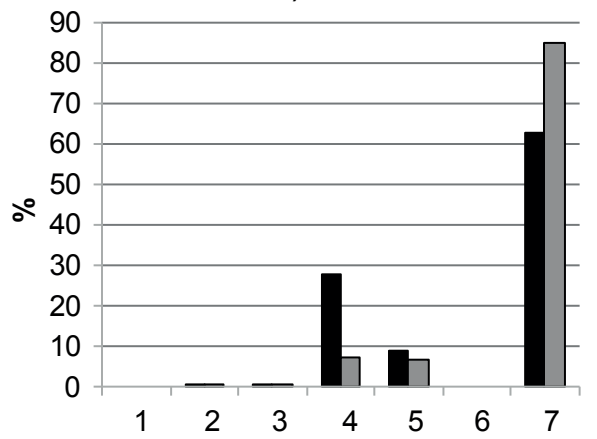

e) OND

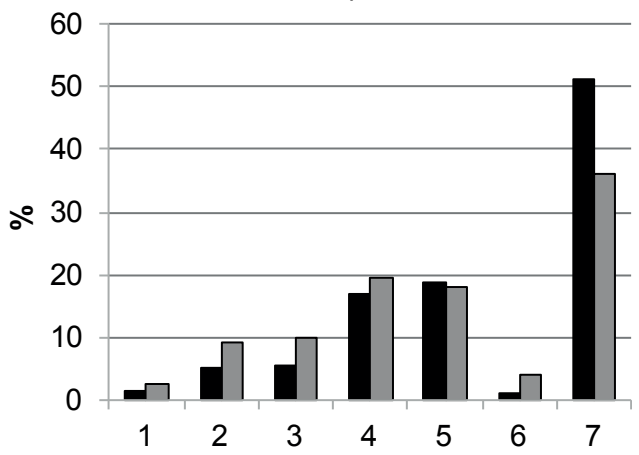

Fig. 3. Comparison of weather type frequencies over the French Alps derived from the D09a climatology (black) and the CT experiment (grey) for 1961-1990, with (a) annual and (b-e) seasonal distributions. The inset table summarizes SAFRAN classification of weather types.

types (Durand et al., 1993). Here, this classification is used to evaluate the ability of both ALADIN CT run and the downscaling method to correctly identify these large-scale circulation patterns.

Figure 3 compares the weather type frequencies obtained over the French Alps during the period 1961-1990, resulting from the CT experiment and D09a climatology, on seasonal and annual time scales. There is good general agreement between the two annual datasets (Fig. 3a). On a seasonal timescale, both experiments indicate that the French Alps are influenced mainly by 3 weather types in summer (types 4, 5 and 7, see upper left panel of Fig. 3) whereas other types occur in winter (Fig. 3b and d). Also, inter-seasonal large-scale features are similar in spring and autumn (Fig. 3c and e). The main discrepancies between the two experiments concern the frequency of strong anticyclones (type 7), which is underestimated by CT in all seasons except summer, and the summer heavy precipitation (type 4 ), which is systematically less frequent in $\mathrm{CT}$.

\subsection{Air temperature and precipitation}

The degree of reliability of the analogue method in reproducing the reference D09a climate on the 1961-1990 period is assessed by considering statistical distributions of nearsurface temperature and precipitation. 

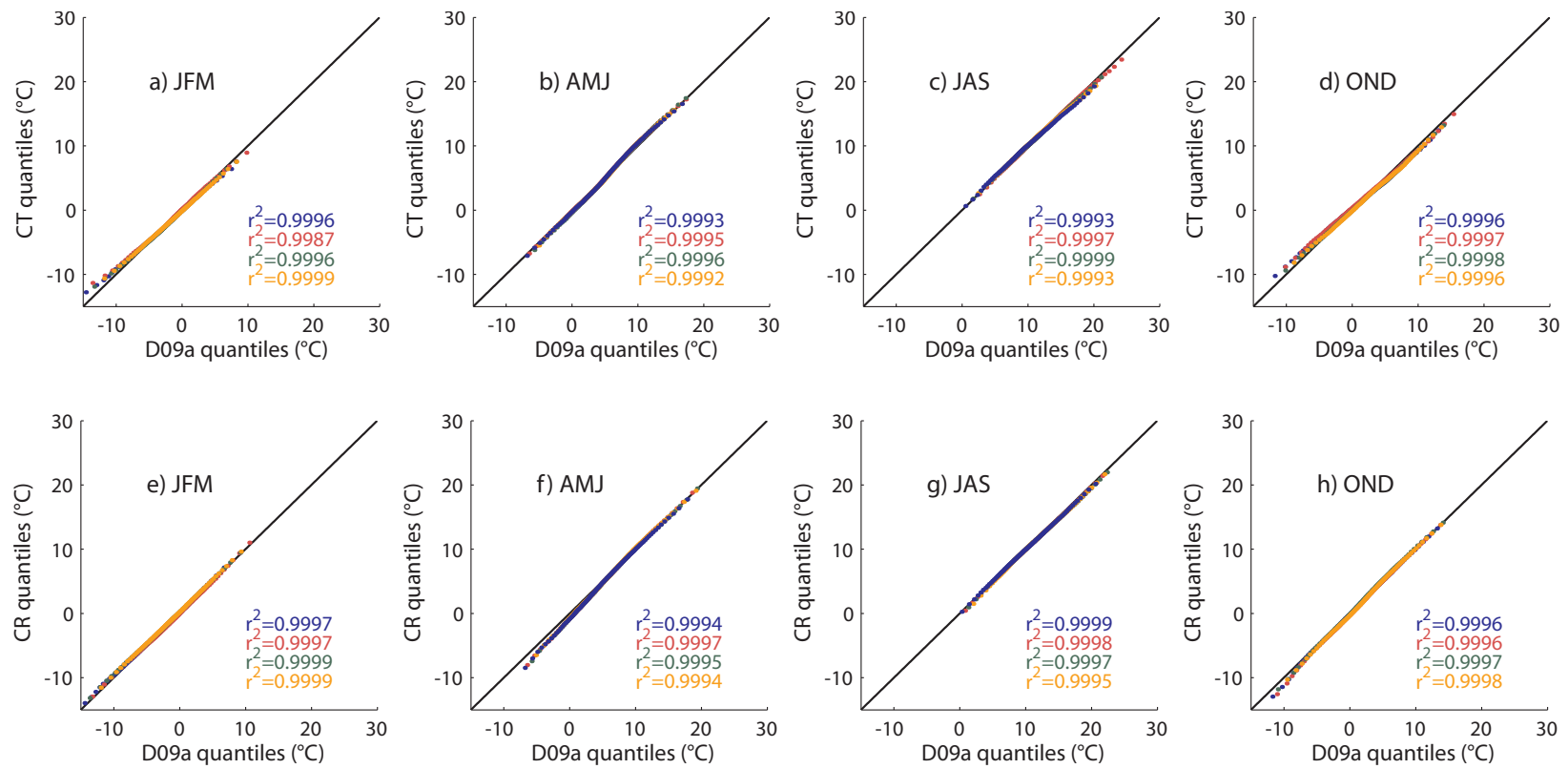

Fig. 4. Seasonal T2m quantile-quantile diagrams $\left({ }^{\circ} \mathrm{C}\right)$ obtained in the (a-d) CT and (e-h) CR experiments at $1800 \mathrm{~m}$ a.s.l. for the Mont-Blanc (blue), Grandes Rousses (red), Queyras (green) and Ubaye (orange) massifs (see Fig. 1 for location). $r^{2}$ is the correlation coefficient between the simulated and D09a quantiles for each massif.
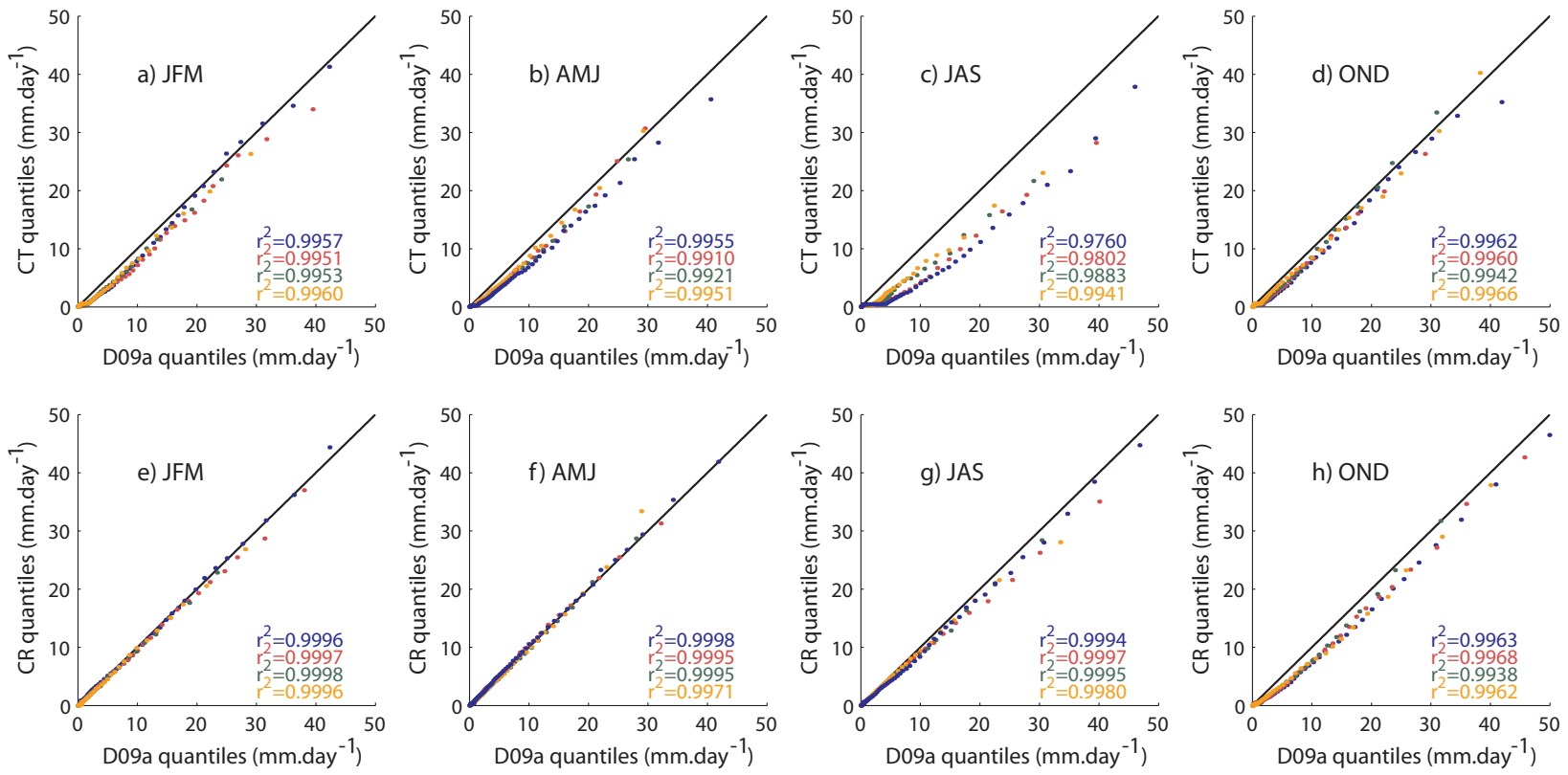

Fig. 5. Same as Fig. 4, but for precipitation.

Figure 4 shows the seasonal quantile-quantile (q-q) diagrams of T2m in the CT (upper row) and CR (lower row) experiments. Figure 5 illustrates similar results for precipitation. Results are presented at $1800 \mathrm{~m}$ a.s.l. and for 4 massifs located in the different regions of the French Alps: the Mont Blanc massif (MB) in the Northern Alps, the Grandes Rousses (GR) in the Central Alps, the Queyras (Qu) in the
Southern Alps and the Ubaye (Ub) in the Extreme Southern Alps (see Fig. 1 for location). Such q-q plots provide synthetic comparisons of statistical distributions, in plotting a set of paired samples of same probability. These figures are thus useful to validate the regional and seasonal patterns of the downscaled climatology. 

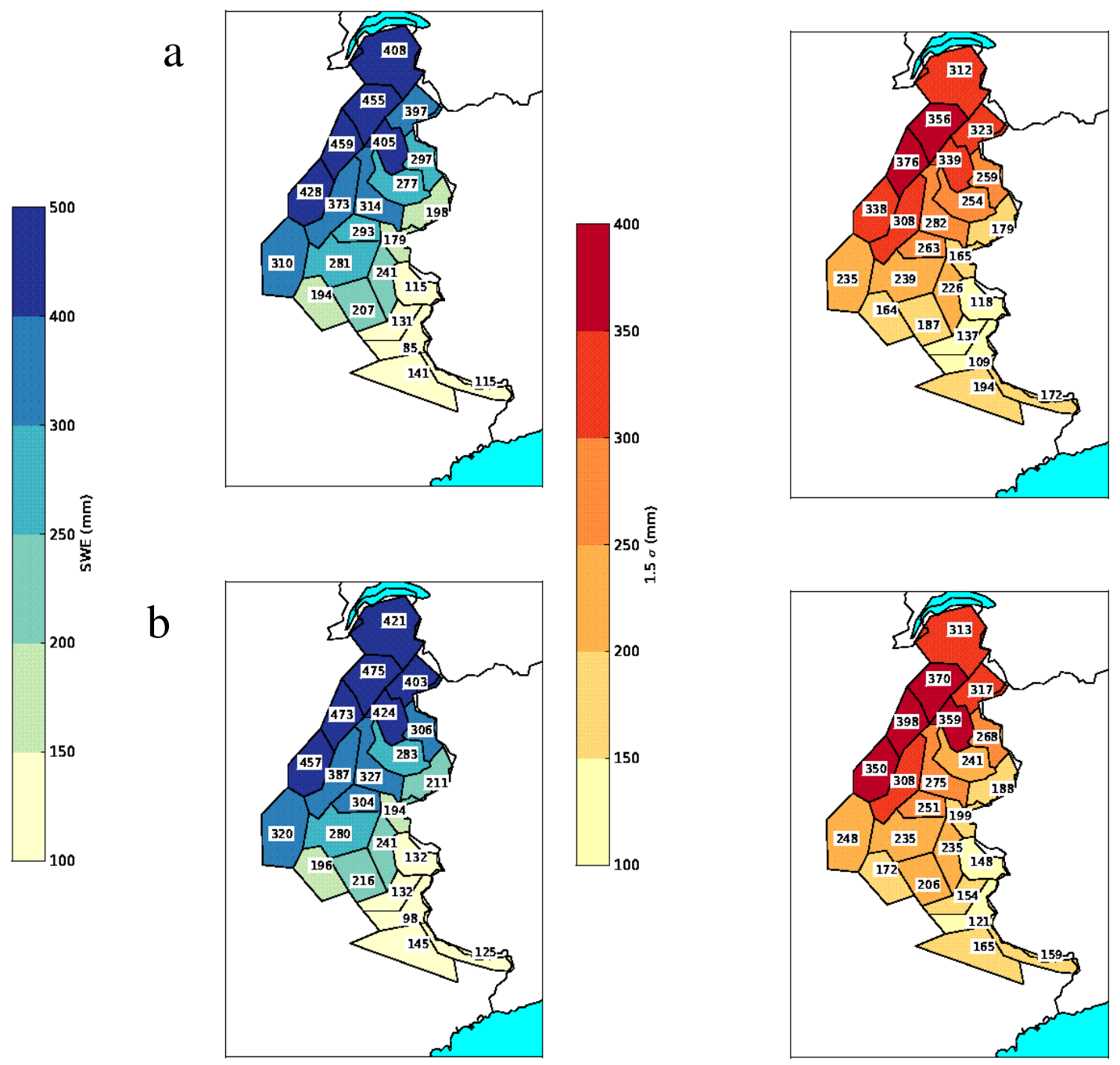

Fig. 6. Mean winter (JFM) values (left) and 1.5 standard deviation (right) of the snow water equivalent (SWE) at $1800 \mathrm{~m}$ a.s.1. for (a) the CT experiment and (b) D09b climatology, for 1961-1990.

Results obtained for T2m suggest fairly good agreement between the D09a climatology and the ALADIN outputs treated in the CT experiment for all the selected massifs and seasons (Fig. 4a-d). As expected, this correlation is improved in the CR experiment (Fig. 4e-h), in which possible sources of errors related to the use of RCM predictors have been removed. In addition, a Kolmogorov-Smirnoff (KS) and a Khi 2 test were conducted to compare the the D09 and CT temperature probability density functions (PDFs). Results of these tests at a $5 \%$ level of significance are positive for the annual and seasonal temperatures and all massifs.

For precipitation, the CT climatology seems to be drier than the D09a climatology, particularly in summer (Fig. 5ad). As for temperatures, the seasonal correlation between simulated and reference precipitation distributions is generally improved in the CR experiment (Fig. 5e-h). However, in the CT experiment, precipitation intensities are still under- estimated, particularly in summer and, to a lesser extent, in autumn. The KS and Khi2 tests also provide contrasted diagnostics. For annual precipitation, the Khi2 test is always true whereas the KS test is rejected for 4 massifs of the Central Alps. In addition, for seasonal precipitation, both tests provide negative results, especially in the Northern Alps in winter for the KS test and in most of the massifs in summer for both tests.

The results shown in Figs. 4 and 5 are confirmed on the annual time-scale by Table 2, which gives the annual mean values of T2m and daily precipitation for each massif together with the standard deviations for both the CT experiment and the D09a climatology. The difference between annual mean $\mathrm{T} 2 \mathrm{~m}$ of the two datasets reaches $\sim 0.3^{\circ} \mathrm{C}$ (Chartreuse massif, Table 2), a value which is well below the intrinsic error of SAFRAN reanalysis, about $1^{\circ} \mathrm{C}$ (Durand et al., 2009a). Moreover, annual mean precipitation at $1800 \mathrm{~m}$ a.s.l. 

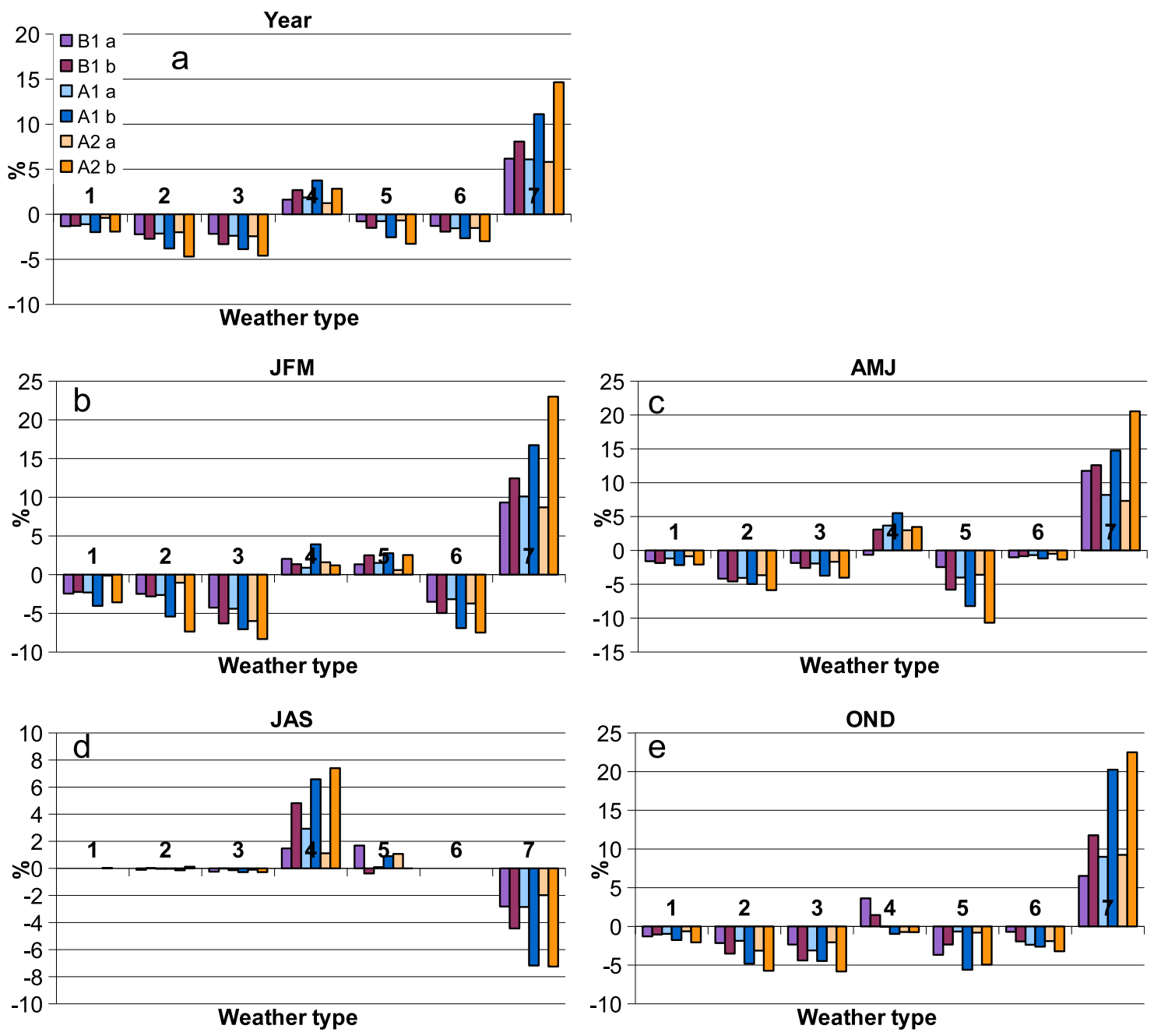

Fig. 7. Changes in \% in weather type annual and seasonal frequency over the French Alps for the periods 2021-2050 and 2071-2100 (subscripts a and b respectively) with respect to frequencies simulated for the period 1961-1990 (CT experiment, see Fig. 2), for different scenarios (B1, A1B and A2). The weather type classification is the same as for Fig.2.

is underestimated by $10 \%$ (Champsaur, Alpes Azuréennes) to $\sim 20 \%$ (Haute-Maurienne) on all massifs (Table 2). Standard deviation values shown in Table 2 also suggest that the downscaled reference ALADIN series reproduces the interannual variability of both $\mathrm{T} 2 \mathrm{~m}$ and precipitation with good confidence.

Our method thus seems to perform better for temperature than precipitation fields. A possible reason is that the latter are not explicitly taken into account in the analogy criterion. Moreover, better correlations between simulated and reference values are generally obtained in the CR rather than in the CT experiment, suggesting that the use of ALADIN instead of reference ERA40 fields as predictors introduces a supplementary error in the downscaling. This error may stem from different parametrization between the ALADIN and ERA40 models, such as the description of the topography and physical processes. In particular, the observed nega- tive bias in precipitation may be explained by the difficulty, common in regional climate modelling, of correctly simulating convective storms that are frequent in summer over Europe. Although their impact on simulated snow cover is expected to be negligible, we choose to correct the discrepancies between the statistical distributions of the D09a (reference) and CT (simulated) climatologies with a quantilequantile method (Déqué, 2007). This approach is often used to correct RCM bias (e.g. Boé et al., 2007; Alpert et al., 2008; Kallache et al., 2011). Here, for each SAFRAN variable, a seasonal correction is applied to each quantile of the distribution according to the massif and elevation.

\subsection{Snow water equivalent}

Maps of mean values and standard deviations of winter snow water equivalent (SWE) at $1800 \mathrm{~m}$ a.s.l. for the reference period 1961-1990 are shown in Fig. 6. These results were 

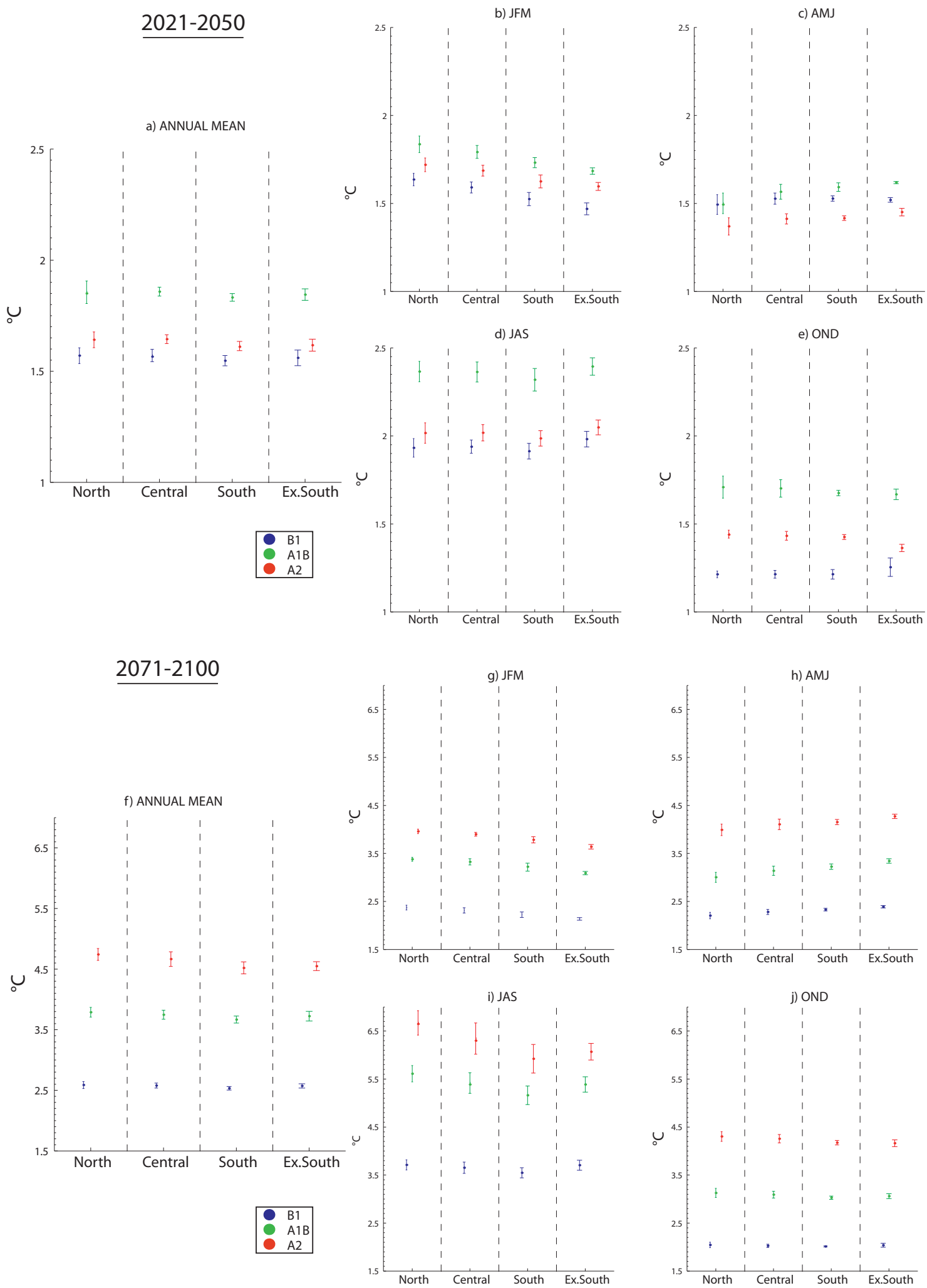

Fig. 8. Changes in annual and seasonal mean T2m at $1800 \mathrm{~m}$ a.s.l. over the Northern, Central, Southern and Extreme Southern French Alps, for the scenarios B1 (blue), A1B (green) and A2 (red) and for the periods 2021-2050 (top panels) and 2071-2100 (bottom panels) with respect to results of the $\mathrm{CT}$ experiment. The error bars indicate 1.5 standard deviation. 
Table 2. Comparison of annual T2m $\left({ }^{\circ} \mathrm{C}\right)$ and precipitation $\left(\mathrm{mm} \cdot \mathrm{d}^{-1}\right)$ means and standard deviation over the Alps in the CT experiment and the D09a climatology, and the differences between the mean values obtained in the two experiments.

\begin{tabular}{|c|c|c|c|c|c|c|c|c|c|c|c|}
\hline \multirow{3}{*}{ Zone } & \multirow{3}{*}{ Massif } & \multicolumn{4}{|c|}{ CT } & \multicolumn{4}{|c|}{$\begin{array}{c}\text { D09a } \\
\text { D }\end{array}$} & \multicolumn{2}{|c|}{$\begin{array}{c}\text { Differences of } \\
\text { means (CT-D09a) }\end{array}$} \\
\hline & & \multicolumn{2}{|c|}{$\mathrm{T} 2 \mathrm{~m}$} & \multicolumn{2}{|c|}{ Precipitation } & \multicolumn{2}{|c|}{$\mathrm{T} 2 \mathrm{~m}$} & \multicolumn{2}{|c|}{ Precipitation } & \multirow[b]{2}{*}{$\mathrm{T} 2 \mathrm{~m}$} & \multirow[b]{2}{*}{ Precipitation } \\
\hline & & Mean & $\sigma$ & Mean & $\sigma$ & Mean & $\sigma$ & Mean & $\sigma$ & & \\
\hline \multirow[t]{6}{*}{ Northern Alps } & Chablais & 3.26 & 0.58 & 4.59 & 0.97 & 3.09 & 0.55 & 5.16 & 0.80 & 0.17 & -0.57 \\
\hline & Aravis & 3.37 & 0.57 & 4.84 & 1.04 & 3.19 & 0.57 & 5.45 & 0.87 & 0.18 & -0.61 \\
\hline & Bauges & 3.45 & 0.58 & 4.43 & 1.03 & 3.20 & 0.58 & 5.02 & 0.98 & 0.25 & -0.59 \\
\hline & Chartreuse & 3.65 & 0.59 & 4.71 & 1.01 & 3.38 & 0.61 & 5.41 & 0.84 & 0.27 & -0.70 \\
\hline & Mont Blanc & 3.33 & 0.55 & 4.33 & 0.90 & 3.22 & 0.55 & 4.91 & 0.77 & 0.11 & -0.58 \\
\hline & Beaufortain & 3.53 & 0.57 & 3.98 & 0.92 & 3.39 & 0.56 & 4.56 & 0.79 & 0.14 & -0.58 \\
\hline \multirow[t]{6}{*}{ Central Alps } & Vercors & 3.73 & 0.58 & 3.76 & 0.79 & 3.50 & 0.64 & 4.35 & 0.68 & 0.23 & -0.59 \\
\hline & Haute-Tarentaise & 3.52 & 0.56 & 2.83 & 0.66 & 3.48 & 0.54 & 3.27 & 0.64 & 0.04 & -0.44 \\
\hline & Vanoise & 3.58 & 0.56 & 2.82 & 0.69 & 3.50 & 0.52 & 3.24 & 0.58 & 0.08 & -0.42 \\
\hline & Maurienne & 3.70 & 0.57 & 3.19 & 0.76 & 3.55 & 0.55 & 3.63 & 0.62 & 0.15 & -0.44 \\
\hline & Belledonne & 3.66 & 0.57 & 4.22 & 0.94 & 3.46 & 0.56 & 4.80 & 0.74 & 0.20 & -0.58 \\
\hline & Grandes Rousses & 3.75 & 0.57 & 3.11 & 0.79 & 3.62 & 0.55 & 3.49 & 0.66 & 0.13 & -0.38 \\
\hline \multirow[t]{8}{*}{ Southern Alps } & Haute Maurienne & 3.69 & 0.55 & 2.42 & 0.58 & 3.69 & 0.52 & 2.86 & 0.64 & 0 & -0.44 \\
\hline & Thabor & 3.80 & 0.56 & 2.30 & 0.58 & 3.76 & 0.54 & 2.65 & 0.57 & 0.04 & -0.35 \\
\hline & Oisans & 3.86 & 0.56 & 3.30 & 0.76 & 3.77 & 0.58 & 3.68 & 0.67 & 0.09 & -0.38 \\
\hline & Pelvoux & 3.99 & 0.56 & 2.96 & 0.74 & 3.97 & 0.56 & 3.31 & 0.72 & 0.02 & -0.35 \\
\hline & Champsaur & 4.06 & 0.56 & 3.04 & 0.68 & 4.03 & 0.59 & 3.34 & 0.66 & 0.03 & -0.30 \\
\hline & Dévoluy & 3.92 & 0.57 & 2.94 & 0.63 & 3.82 & 0.63 & 3.26 & 0.64 & 0.10 & -0.32 \\
\hline & Queyras & 4.01 & 0.56 & 1.93 & 0.47 & 4.04 & 0.53 & 2.23 & 0.45 & -0.03 & -0.30 \\
\hline & Parpaillon & 4.34 & 0.55 & 2.30 & 0.55 & 4.39 & 0.52 & 2.57 & 0.47 & -0.05 & -0.27 \\
\hline \multirow[t]{3}{*}{ Extreme South Alps } & Ubaye & 4.58 & 0.55 & 2.27 & 0.51 & 4.61 & 0.52 & 2.52 & 0.54 & -0.03 & -0.25 \\
\hline & Alpes Azuréennes & 4.83 & 0.55 & 2.92 & 0.73 & 4.83 & 0.52 & 3.22 & 0.68 & 0 & -0.30 \\
\hline & Mercantour & 4.84 & 0.52 & 3.25 & 0.88 & 4.92 & 0.47 & 3.62 & 0.82 & -0.08 & -0.37 \\
\hline
\end{tabular}

either obtained by forcing CROCUS with the climate data derived from ALADIN (CT experiment) and statistically corrected by a q-q method (Fig. 6a) or directly selected in the D09b climatology (Fig. 6b). The differences in mean SWE between downscaled and reference data are of the order of magnitude of $10 \mathrm{~mm}$ (Fig. 6a). This value is well below the signal variability, as standard deviations are about 10 times larger (Fig. 6b). Thus, values of SWE at $1800 \mathrm{~m}$ a.s.l. derived from ALADIN fields are generally in good agreement with the D09b climatology of each massif, showing a similar decreasing North-South gradient over the Alps. Results at other elevations (not shown) also suggest that the downscaling method reproduces both mean and interannual variability of current SWE with reasonable confidence.

\section{Changes in climate and snow cover}

In this section, changes in climate and snow cover derived from the ALADIN scenarios are presented. For the sake of clarity, some results are illustrated on clusters of massifs (Northern, Central, Southern and Extreme Southern Alps, see Fig. 1) presenting similar climate characteristics, as defined in Durand et al. (2009b).

\subsection{Changes in frequency of weather types}

Figure 7 illustrates changes in weather type frequency obtained for the 2021-2050 and 2071-2100 periods with respect to the CT experiment (Fig. 3). Generally, changes are larger at the end of the century than earlier and reveal a marked influence of the greenhouse gases concentration. Thus, for the 2071-2100 period, the A2 scenario leads to changes that are generally larger than in the A1B scenario, whereas the B1 scenario leads to smoother evolutions, in agreement with changes expected on a global scale (IPCC, 2007). On the annual time-scale, our results suggest a significantly increasing frequency of large, stable anticyclones (weather type 7) at the expense of the other weather types (Fig. 7a). These synoptic evolutions over France are consistent with the expected large increase in sea level pressure over the Mediterranean Sea for this period (Boé et al., 2009). On the seasonal time-scale, large anticyclones (weather type 7) seem to become more frequent in winter, spring and autumn (Fig. 7b, c and e), but sparser in summer, a season 

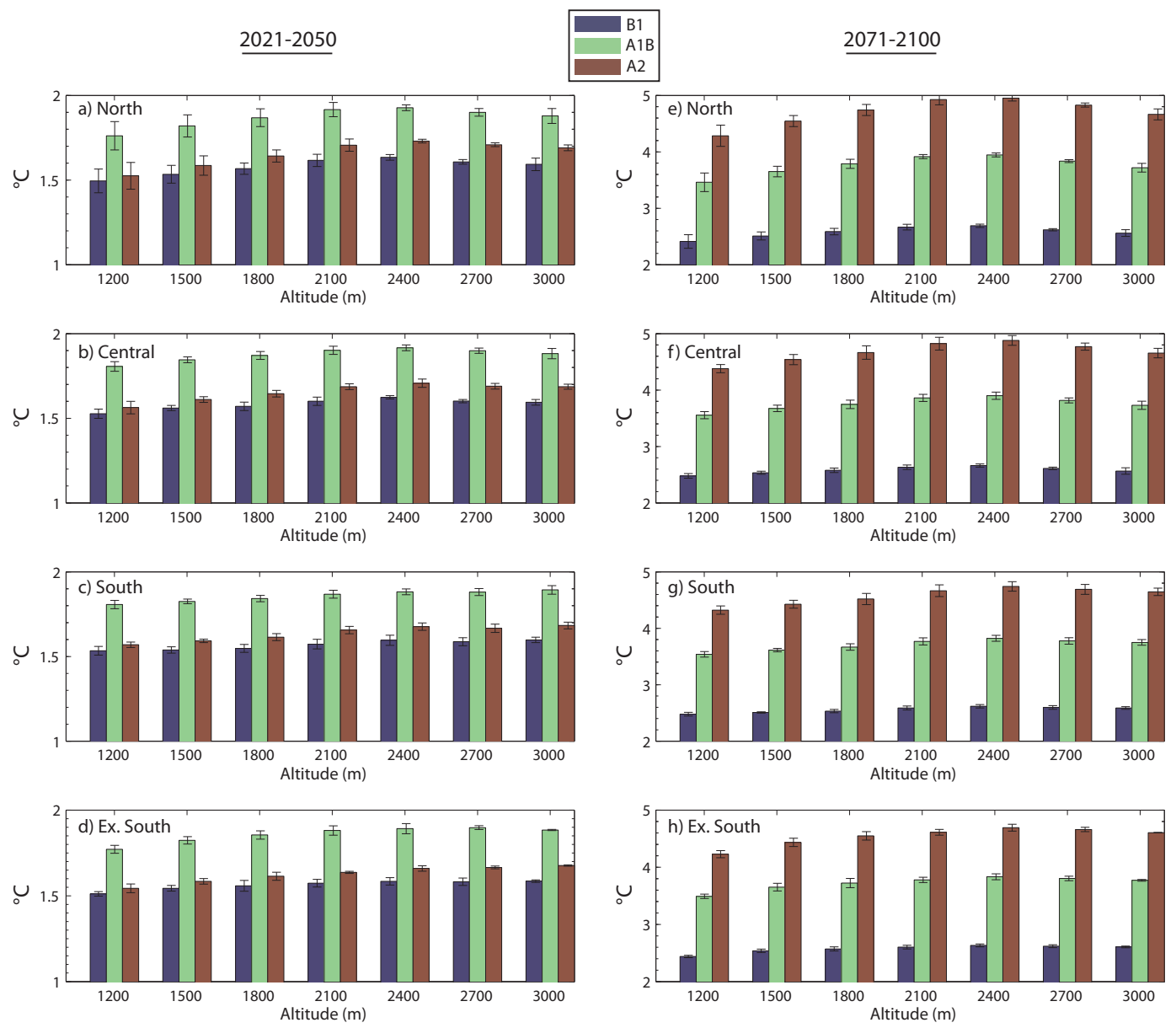

Fig. 9. Changes in (a) annual mean T2m as a function of altitude over the (a-b) Northern, (c-d) Central, (e-f) Southern and (g-h) Extreme Southern French Alps, for the scenarios B1 (blue), A1B (green) and A2 (red) and the periods 2021-2050 (left panels) and 2071-2100 (right panels) with respect to results of the CT experiment. The error bars indicate 1.5 standard deviation. Note the different scales.

dominated by frequent north-westerly and south-westerly perturbed flows (weather type 4) (Terray et al., 2004).

\subsection{Changes in surface temperature}

Figure 8 shows the annual and seasonal T2m changes at $1800 \mathrm{~m}$ a.s.l. over the Northern, Central, Southern and Extreme Southern Alps (Fig. 1), for 2021-2050 and 2071-2100 and for all scenarios with respect to the CT experiment. Figure 9 shows the altitudinal gradient of the annual $\mathrm{T} 2 \mathrm{~m}$ changes for the same regions, periods and scenarios.

For all scenarios, results suggest significant warming in the Alps over the next century. Mid-century projections indicate a mean annual warming of about $1.5-2{ }^{\circ} \mathrm{C}$ (Figs. $8 \mathrm{a}$ and 9a-d), with the largest changes obtained for the A1B scenario. In agreement with trends expected at the global scale, the spread of the annual mean temperature change as a function of the emission scenario increases at the end of the century, ranging from $\sim 2.5-5^{\circ} \mathrm{C}$ for the least (B1) and the most (A2) emissive scenarios respectively (Figs. $8 \mathrm{f}$ and $9 \mathrm{e}-\mathrm{h}$ ).
The temperature changes simulated for each scenario and period seem relatively uniform from the Northern to the Extreme Southern Alps (Fig. 8a, b) and for the elevation range considered (Fig. 9). This is probably because our method does not add any spatial variability to the input D09a climatology, as ALADIN T2m fields are generally smooth over the French Alps (not shown). Thus, these results suggest that climate change will probably affect mean temperatures over the entire Alps, and that the future Alpine climate will be characterized by an increasing North-South temperature gradient (Table 2 and Durand et al. (2009a)). Changes obtained for the A1B scenario are in agreement with results obtained on the European Alps in the framework of the ENSEMBLES project. In this project, a rather uniform temperature increase of about $1.8-2{ }^{\circ} \mathrm{C}$ was simulated for the $2021-2050$ period by a set of 16 weighted RCMs (van der Linden and Mitchell, 2009). In addition, Beniston (2011) suggested a warming of about $3-4{ }^{\circ} \mathrm{C}$ in winter and $6-7^{\circ} \mathrm{C}$ in summer over the Swiss Alps for the 2071-2100 period and the A2 scenario, which is 

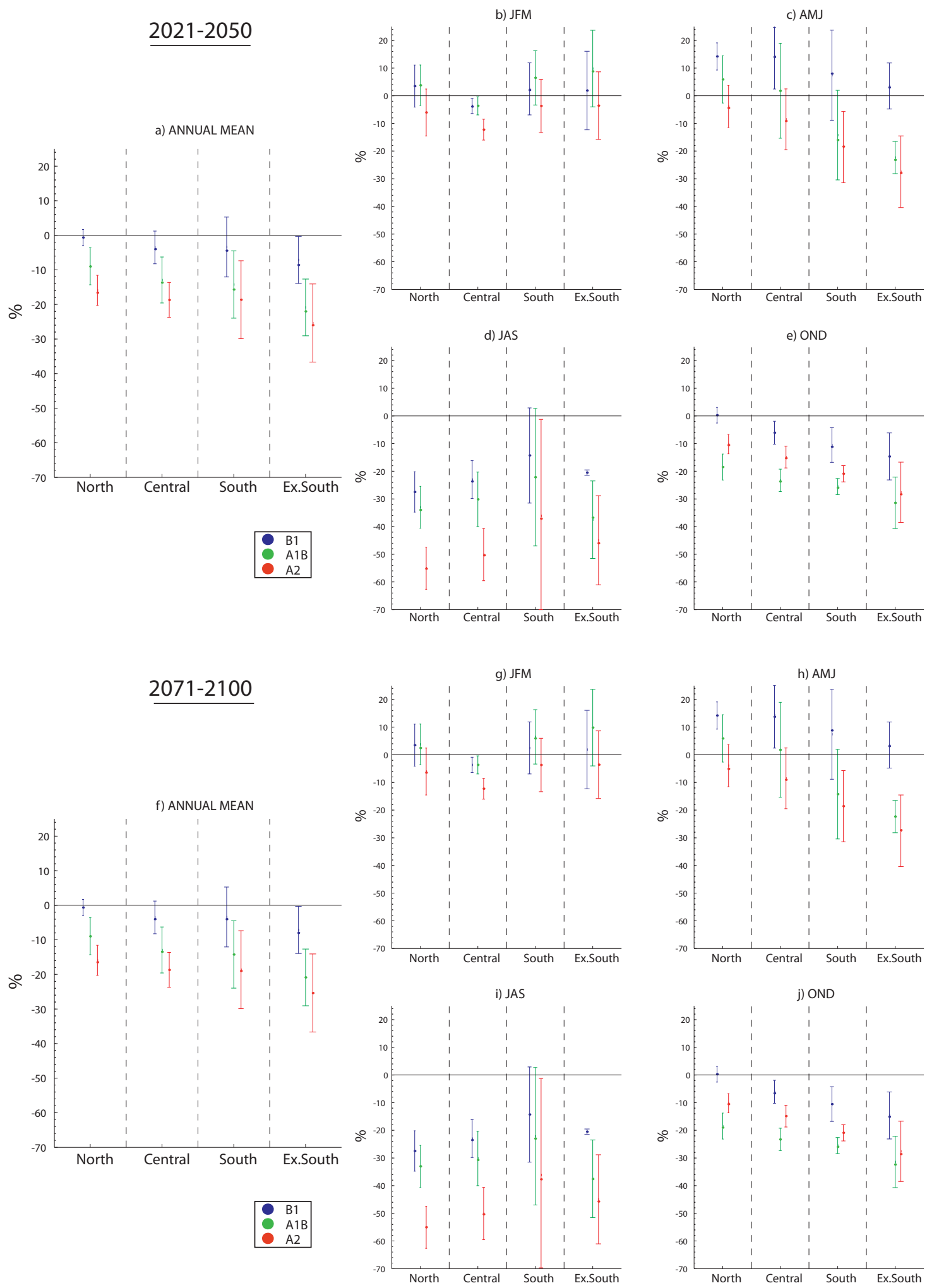

Fig. 10. Changes in (a) annual and (b-e) seasonal mean precipitation at 1800 ma.s.l. over the Northern, Central, Southern and Extreme Southern French Alps, for the scenarios B1 (blue), A1B (green) and A2 (red) and the periods 2021-2050 (left panels) and 2071-2100 (right panels) with respect to results of the CT experiment. The error bars indicate 1.5 standard deviation. 

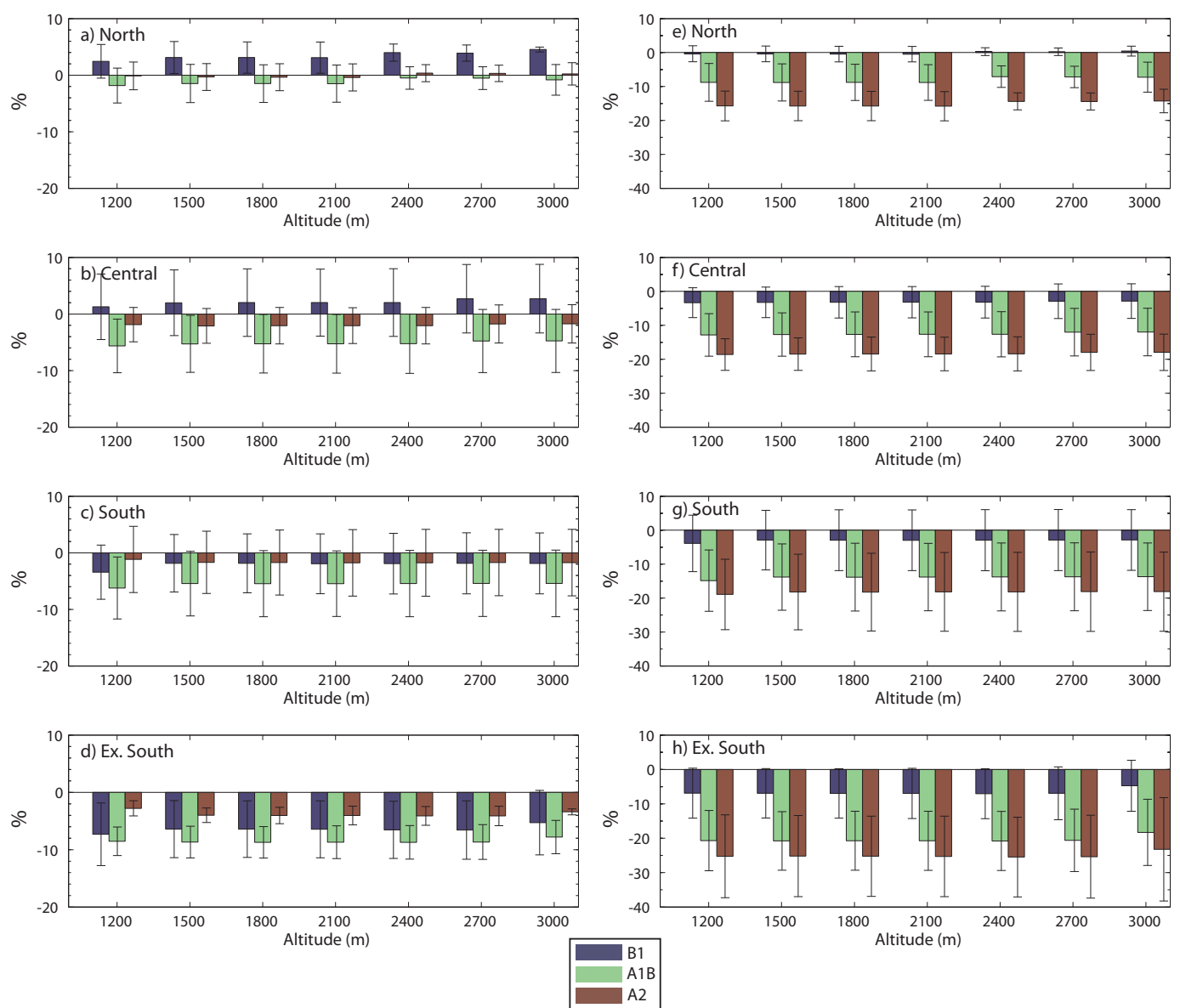

Fig. 11. Changes in (a) annual mean precipitation as a function of altitude over the (a-b) Northern, (c-d) Central, (e-f) Southern and (g-h) Extreme Southern French Alps, for the scenarios B1 (blue), A1B (green) and A2 (red) and the periods 2021-2050 (left panels) and 2071-2100 (right panels) with respect to results of the CT experiment. The error bars indicate 1.5 standard deviation. Note the different scales.

in agreement with the trends simulated in our study over the Northern Alps.

There is a seasonal signature of the warming, with a winter (summer) temperature anomaly that is smaller (larger) than the annual signal. This seasonal signature is clearer at the end of the century, with winter anomalies ranging from 2 to $4{ }^{\circ} \mathrm{C}$, and summer anomalies varying between 3 and $7{ }^{\circ} \mathrm{C}$ according to the scenario (Fig. 8g and i $-3.2 \mathrm{~d}$ and h). Spring and autumn anomalies display similar features, with intermediate values ranging from 2 to $4.5^{\circ} \mathrm{C}$ for the $2071-2100$ period (Fig. $8 \mathrm{~h}$ and j).

The annual temperature changes over the Alps provided by the analogue method were compared to these directly simulated by ALADIN on the grid points located in the Alps (Fig. 1). These changes are in agreement with each other and range, respectively, from 1.7 to $2^{\circ} \mathrm{C}$ for the $2021-2050$ period and 3.2 to $3.9^{\circ} \mathrm{C}$ for the $2071-2100$ period for the A1B scenario.

\subsection{Precipitation changes}

Figure 10 shows the annual and seasonal precipitation anomalies at $1800 \mathrm{~m}$ a.s.l. for the 2021-2050 and 2071-2100 periods and all scenarios. Simulated precipitation changes for both 2021-2050 and 2071-2100 are highly variable according to the scenario, season and region of the French Alps and uncertainties are much larger than for temperature. Some trends can however be identified for the end of the century. At this time, annual mean anomalies show a deficit in precipitation down to $\sim 25 \%$ for the $\mathrm{A} 1 \mathrm{~B}$ and $\mathrm{A} 2$ scenarios, and no significant evolution for the B1 scenario (Fig. 10, bottom panels). The seasonal evolution is more contrasted, suggesting that the annual precipitation decrease simulated for the A1B and A2 scenarios is primarily due to drier summers (down to $-55 \%$ precipitation in the Extreme Southern Alps for the A2 scenario) and, to a lesser extent, autumns and springs (Fig. $10 \mathrm{i}, \mathrm{j}$ and $\mathrm{h}$ ), at least in the Southern and Extreme Southern Alps. The B1 scenario seems to be the wettest one on all regions except in winter. Interestingly, in this season, all scenarios provide similar results with 

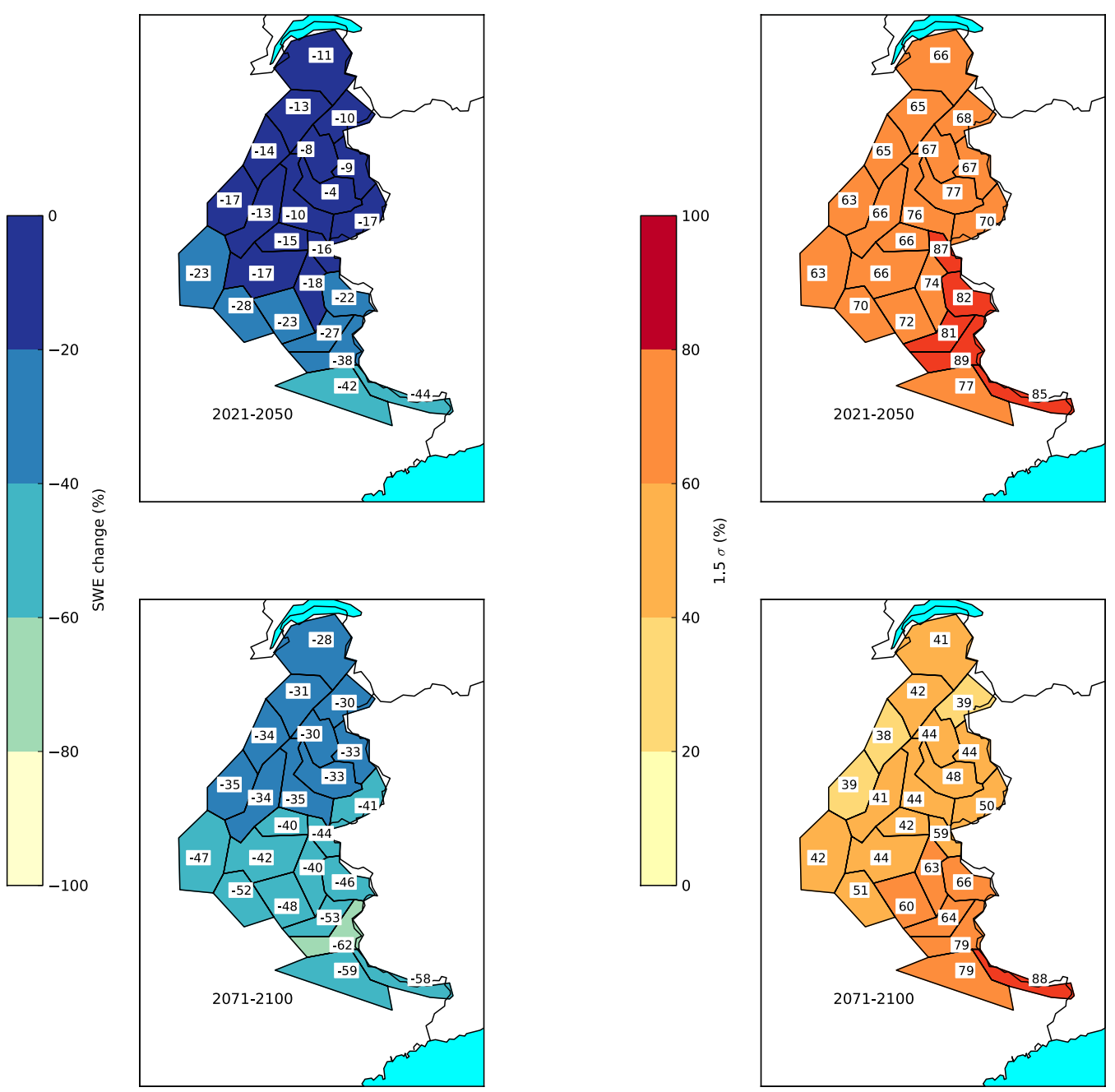

Fig. 12. Changes in winter snow water equivalent (\%) at $1800 \mathrm{~m}$ a.s.l. (left panel) and 1.5 standard deviation (right panels) over the French Alps, for the scenario B1 and the periods 2021-2050 (top panels) and 2071-2100 (bottom panels) with respect to results of the CT experiment.

no significant precipitation changes with respect to signal variability (Fig. 10g) despite anticyclonic situations that are likely to get more frequent in the future (Fig. 7b). The regions most affected by drying seem to be located in the Southern and Extreme Southern Alps, particularly during the interseasons (Fig. 10h and j). Thus, the current precipitation gradient observed over the Alps, decreasing from North to South (Table 2 and Durand et al. (2009a)), might be strengthened in the future. In the Southern and Extreme Southern Alps, the relative summer precipitation deficit seems to be slightly smaller than in the other regions, which might be related to wet westerly/north-westerly flows being more frequent in the future, or more frequent dry anticyclonic regimes (as suggested in Fig. 7). However, the question of the link between changes in large-scale circulation and local climate evolution would deserve deeper analysis and is outside the scope of this study. Comparison of our results over the French Northern Alps with those obtained over the Swiss Alps (Benis- ton, 2011) for the end of the century reveals that the summer precipitation deficit is on the same order of magnitude in both countries, with a reduction of about 30-50\% in France and $20-40 \%$ in Switzerland. However in winter, precipitation seems to increase by $15-35 \%$ in the Swiss Alps, in contrast to the $0-10 \%$ increase suggested by our results in the Northern Alps. A possible reason for this discrepancy is the difference of parameterization and variability of the RCMs used in both studies.

As in other studies (van der Linden at al., 2009), projections of precipitation trends over the Alpine areas for 20212050 are difficult to interpret, showing very contrasted results according to scenarios, seasons and regions (Fig. 10a-e). In contrast to the end of the century, only the Extreme Southern Alps seem to undergo moderate drying, of less than $10 \%$ on the annual time-scale (Fig. 10a). Seasonal changes suggest that the largest precipitation decreases, of $\sim 15$ to $20 \%$, are expected in autumn (Fig. 10e) in all regions for the A1B and 


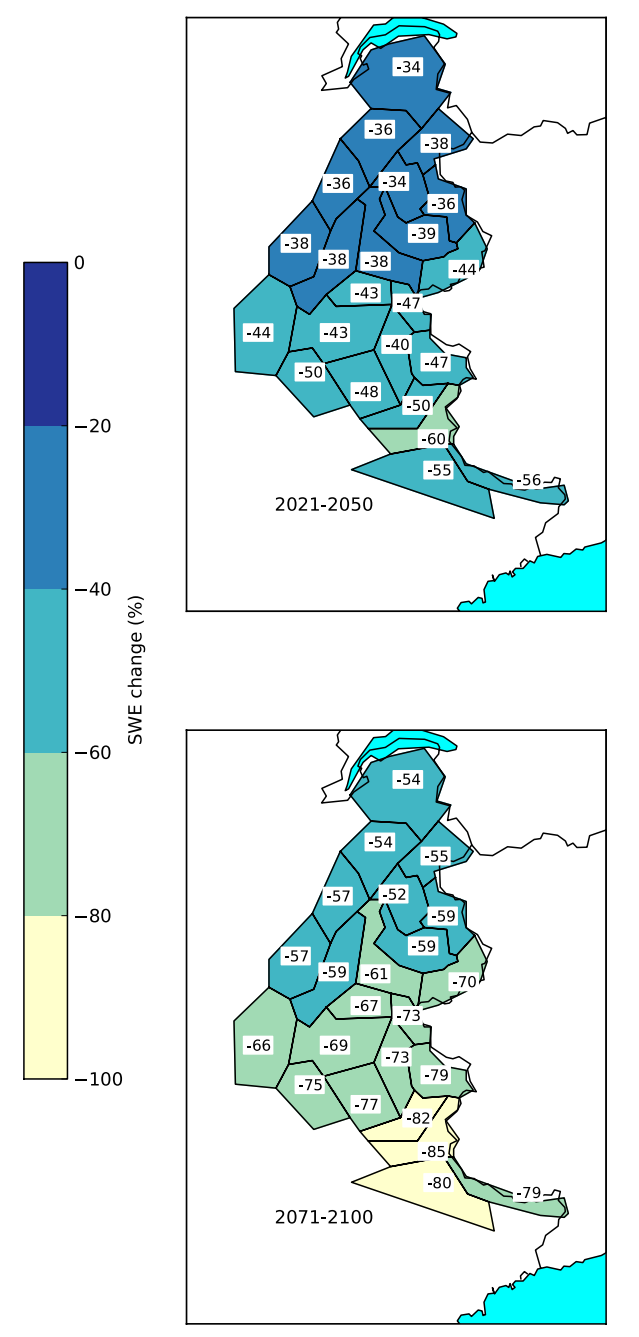

Fig. 13. Same as Fig. 12, but for the scenario A1B.

A2 scenarios and only in the Southern and Extreme Southern massifs for the B1 scenario.

Figure 11 shows the altitudinal gradients of annual precipitation changes over the main Alpine regions for 2021-2050 and 2071-2100 and all scenarios. As for temperatures, the simulated precipitation anomalies do not seem to depend on the altitude. This suggests that the orographic gradient currently observed in the different regions of the Alps (Durand et al., 2009a) may be qualitatively the same in the future.

\subsection{Changes in snow water equivalent}

Figures 12,13, 14 show maps of the relative change in winter snow water equivalent (SWE) and the standard deviation at $1800 \mathrm{~m}$ a.s.l. for the different scenarios with respect to current SWE (Fig. 6b). The current decreasing trend in snow cover over recent decades reported by D09a seems to continue in the future for all massifs and scenarios. In the B1 scenario, the decrease in SWE is significantly less than for

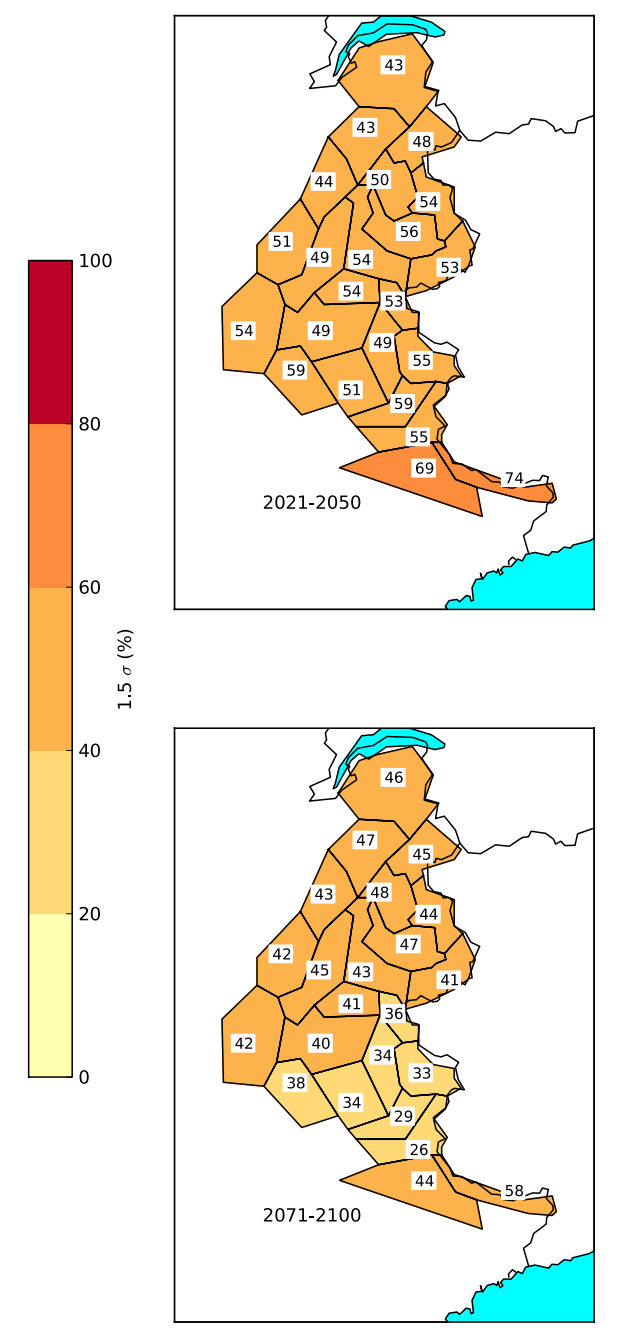

the other two scenarios, particularly in the northern massifs (Fig. 12). In consequence, only at the end of the century do SWE losses in the B1 scenario reach levels simulated for the earlier period in the A1B (Fig. 13) and A2 scenarios (Fig. 14). Moreover, at the end of the century, the expected decrease under the worst case A2 scenario (Fig. 14) is about twice that projected for the B1 scenario in the Alps, and even more when only the Northern and Central Alps are considered. The impact of climate change results in a dramatic reduction of SWE, close to $100 \%$ in the southernmost massifs in the A2 scenario, and to a strong North-South SWE gradient in all scenarios.

Relative SWE changes with altitude for the different regions of the Alps are shown in Fig. 15, which suggest a strong altitudinal gradient in the SWE reduction. In the Northern Alps, under B1 conditions, the mean SWE at $1500 \mathrm{~m}$ a.s.l. is likely to decrease by an average of $30 \%$ for 2021-2050 and 55\% for 2071-2100. These ratios increase to, respectively, $50 \%$ and $80 \%$ for these two time periods 


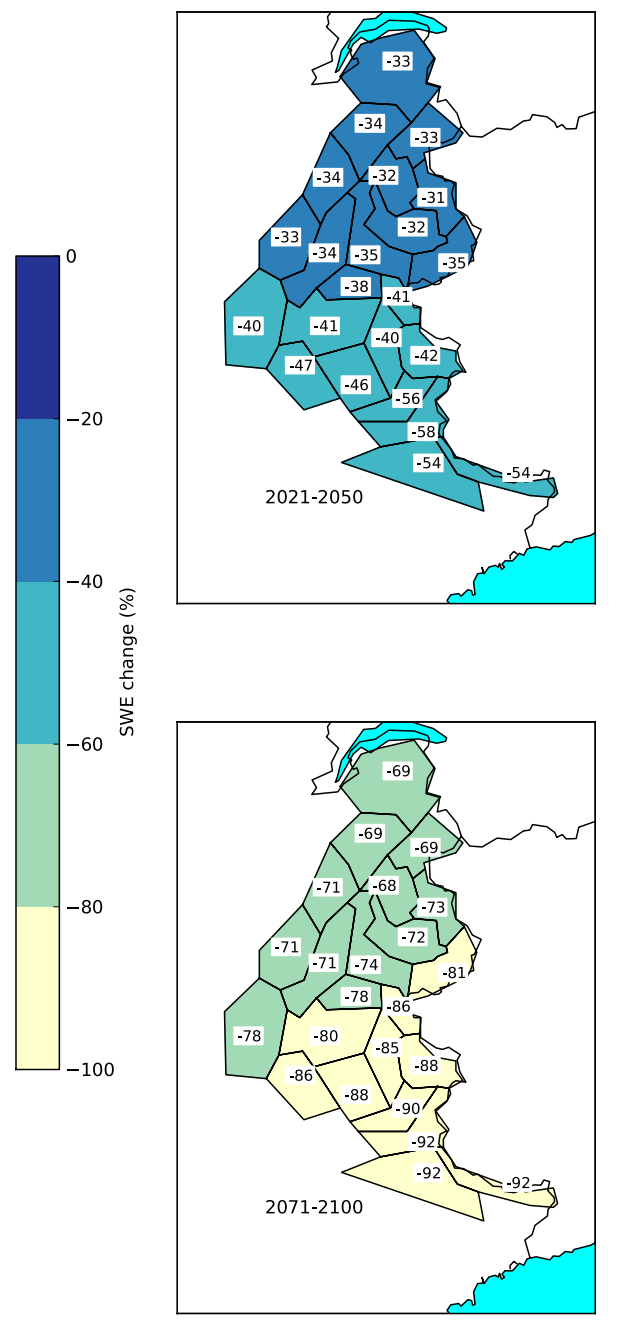

Fig. 14. Same as Fig. 12, but for the scenario A2.

for scenario A2. At $2100 \mathrm{~m}$ a.s.l., mean decreases in SWE of $20 \%$ and $30 \%$ are simulated for the B1 and A2 scenarios, respectively, for 2021-2050. During this period, areas above this altitude are relatively less affected by climate warming, with average decreases in SWE varying by about $10 \%$ and $25 \%$ for the B1 and A2 scenarios, respectively. At the end of the century, this critical altitude seems to rise to $2400 \mathrm{~m}$ a.s.l. for the B1 scenario and higher for the other ones in the Northern Alps.

Snow studies conducted in mid-latitudes regions generally show that snowpack sensitivity to near-surface temperature is higher when the snow is close to its melting point: when the melting point is reached, the incoming energy is used for melting the surface layers, resulting in a decrease of the snow depth. This implies that in the Alps at high elevations, snow cover is mainly governed by precipitation regimes, whereas at lower elevations, all the terms of the energy balance are relevant to describe snow cover evolution. In our experiment, snowpack close to the melting point is more sensitive to small

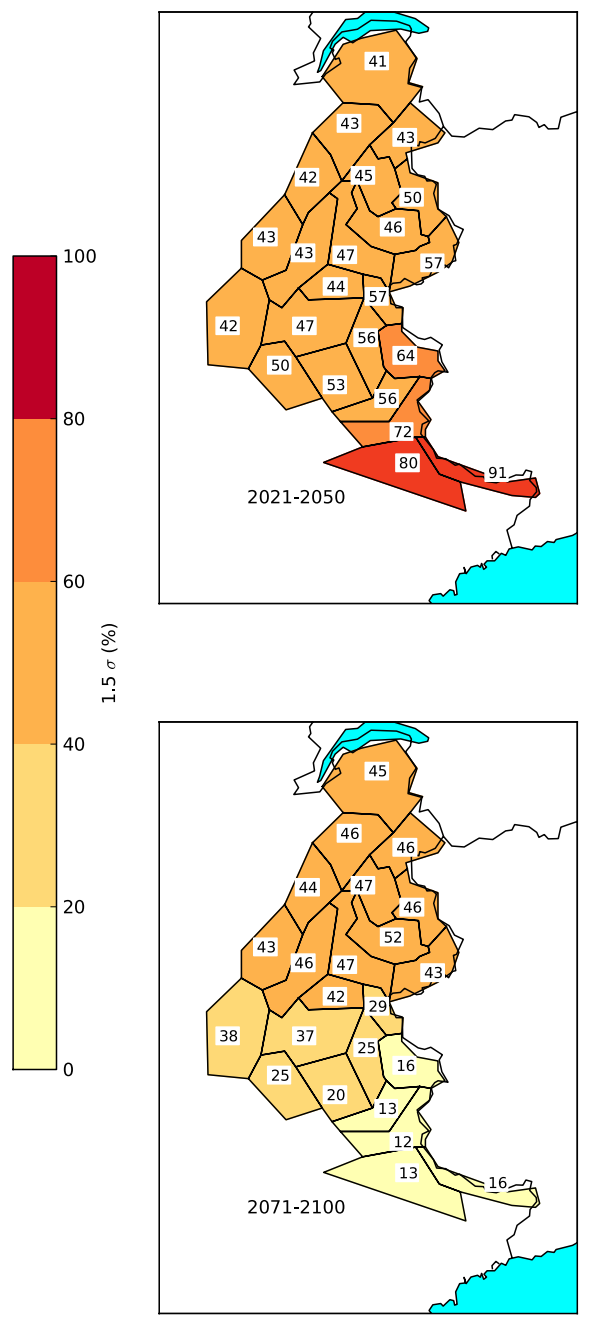

air temperature increase; this concerns snow cover located at low altitudes and in southern regions characterized by generally higher temperature levels. These areas also show large relative SWE changes (Figs. 12, 13 and 14) because of their initial low SWE values. A secondary effect that could explain the snowpack decrease in the southernmost areas is the decrease of precipitation, particularly in autumn (Fig. 10). These results are in agreement with a previous study (Martin et al., 1994) conducted on the same massifs with climatic data of coarser resolution.

Thus, future SWE reduction seems to significantly affect all massifs of the Alps for all scenarios at the end of the century. In particular, for this period, warming may have extremely strong impact at altitudes below $2400 \mathrm{~m}$ a.s.l. and preferentially in the southernmost massifs. Thus, snowpack may become extremely sparse in the Extreme Southern Alps in the $\mathrm{A} 2$ scenario. 

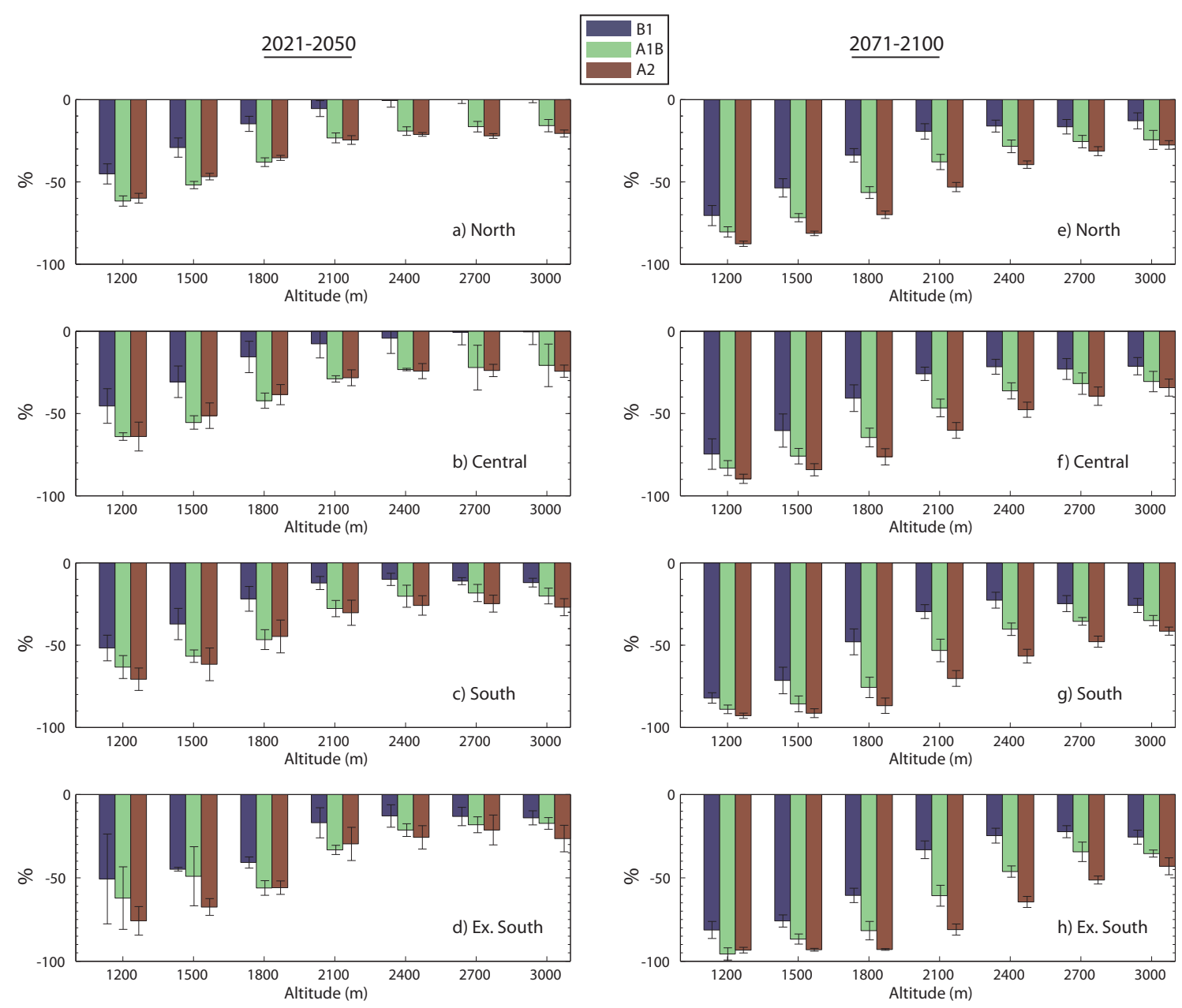

Fig. 15. Mean JFM snow water equivalent (\%) as a function of altitude over the (a-e) Northern, (b-f) Central, (c-g) Southern and (df) Extreme Southern French Alps, for the scenarios B1 (blue), A1B (green) and A2 (red) and the periods 2021-2050 (left panels) and 20712100 (right panels). The error bars indicate 1.5 standard deviation. Note the different scales.

\section{Discussion}

In this study, we have developed a procedure for adapting climate scenarios to snow modelling. This procedure consists of a statistical adaptation of fine-scale RCM fields to the Alpine region. In particular, the method performs an analogue search based on minimizing a simple statistical distance between atmospheric fields of T2m, Z500 and derived from Z500 of the RCM ALADIN and the ERA40 data. The date of the selected ERA40 day is subsequently used to identify the corresponding detailed meteorological situation analysed by SAFRAN over the Alps for that day, available from a previous work (D09a). It is thus assumed that, despite the few atmospheric fields considered here, both large-scale and near-surface processes of the meteorological situation can be characterized with sufficient detail in the analogue method.

The first step of the validation indicated that both the chosen atmospheric fields and the simple statistical criterion were suitable to reconstruct current D09a climatology when a cross analogue search was applied to two distinct ERA40 datasets. The second step of the validation, where analogues were sought between ERA40 and ALADIN fields, suggested that the method tends to underestimate precipitation compared to current climatology, mainly in summer and, to a lesser extent, in autumn. This underestimation probably reflects differences in parametrization of physical processes and topography between the ECMWF and ALADIN models.

The introduction of a statistical q-q correction provided a partial solution to this problem. This kind of correction has many advantages: it is simple, robust and appropriate to treat extreme events. Moreover, the correction, which is applied to a set of initially coherent meteorological data, is relatively small compared to the absolute value of the variables (Figs. 4 and 5), so that it guarantees a certain degree of consistency in the corrected driving parameters of the snow CROCUS model. In addition, the q-q method can account for the annual cycle as it is applied to individual seasons separately. In this study, this correction was applied to temperature, humidity, 
wind velocity, precipitation and cloudiness. A coherent correction was derived from these corrected variables for radiation using a radiation model.

However, an important issue concerning this kind of correction, which is common to many other downscaling studies (Martin et al., 1997; Kallache et al., 2011), is the question of its validity in the future, despite climate change. The underlying idea is that, since the relative frequency of weather types might change in a changing climate, the resulting weather variable distribution may change. This would potentially invalidate the correction function, unless it was done for each regime separately. In our case, the analysis of weather type frequencies between present and future climate indicates that there is no important change between present and future in the frequency of weather types responsible for large precipitation events. Thus, even if this consideration does not validate the correction, is does not rule it out.

Other assumptions are that the statistical relationship between the RCM predictors and the local variables will be the same in the future, that the selected RCM predictors capture the effect of global warming, and that realistic future meteorological situations are contained in the D09a analogues dataset. These assumptions cannot be verified. Nevertheless, an analysis of the mean value of the computed distance (Eq. 1) shows that it increases slightly for future periods and the summer and autumn seasons, i.e. that largely warmer analogues tend to be selected for these seasons in future scenarios. Thus, our method does not seem to be well adapted for the warmest months of the future, for which close analogues probably do not exist in the 1958-2008 database. However, such features are not observed for the winter and spring seasons, so that we expect that this limitation does not significantly affect results of the snow modelling. Moreover, we have verified a posteriori that our method provides results in agreement with characteristic features of climate changes obtained at larger scale by fully dynamical methods.

Despite these limitations, the method presents several advantages. It enables the use of RCM scenarios at an intermediate resolution $(35 \mathrm{~km})$, consistent with the size of the Alpine massifs. At the same time, the finer initial resolution of the ALADIN outputs $(12 \mathrm{~km})$ guarantees a fine representation of the different meteorological features. These fine-scale features, even if interpolated on a coarser $35 \mathrm{~km}$ grid, improves the description of the temporal climate variability. A perspective for this work will nevertheless be to quantify the influence of the RCM output resolution used on the quality of the scenarios obtained at the massif scale. Second, this method, which is computationally efficient compared to other analogue methods as it uses only a limited number of atmospheric and statistical parameters, provides detailed climate scenarios. These scenarios are composed of daily SAFRAN fields which not only provide a full set of meteorological data but also account for massif, slope, altitude and exposition. These parameters are essential for the running of a physically elaborate snow model such as CRO-
CUS. The spatial and daily coherence of the downscaled variables, guaranteed by the use of the SAFRAN fields, is important for the snow applications considered here because it determines the effect of climate on the snow mantle as integrated in time and allows the identification of regional patterns in the snow cover evolution. Finally, using a complex snow model such as CROCUS rather than a simple degreeday model presents several advantages. It allows computation of SWE within the snowpack, as presented in this study. Also, the physical parametrization of CROCUS takes some non-linear feedbacks of climate warming into account that accelerate the snow melt, such as temperature increase within the snowpack, which comes closer to the melting point, or the change in albedo due to changes in snow grain shapes.

Apart from the expected biases of the RCM inputs, which have been corrected, and the inherent uncertainty resulting from the nature of the data used for validation and the downscaling procedure, snowpack simulated in the reference situation adequately reflects current snowpack climatology. Our projections are in agreement with numerous previous studies which underline the likelihood of a marked decrease of the snow cover in temperate regions over the coming decades (Martin and Etchevers, 2005; López et al., 2009). Our results provide further insight into the possible reasons for this SWE reduction, suggesting that simulated SWE reduction may primarily be a result of warming in all seasons, particularly from autumn to April, and possibly of a reduction of precipitation in autumn. In particular, rising temperatures may cause SWE reduction for two reasons: (i) above a given temperature threshold, precipitation falls as rain instead of snow during the snow season (extended winter, running from November to April); (ii) rising near-surface temperatures are indicative of increased surface temperatures, which favour earlier melt of the snow cover, especially in spring. Moreover, significant SWE changes are identifiable, according to the GHG scenario, from 2021-2051, a period for which the climate response is only slightly dependent on the scenario, stressing the strong sensitivity of snow cover to small climate variations. Regions where current mean seasonal temperatures are only slightly negative are particularly sensitive to the simulated SWE reduction, and concern low to mid altitudes and the Southern and Extreme Southern Alps.

\section{Conclusions}

The aim of this study was to evaluate the potential impact of global change on snow cover in the French Alps for the forthcoming decades. Changes were evaluated by a statistical adaptation method where an analogue method was applied to high resolution RCM predictors and provided complete, physically coherent climate series suitable for snow modelling. The focus was on the validation of the method and changes in temperature, precipitation and SWE. The changes were assessed by comparing climate and snowpack 
simulations for the control period (1961-1990) and those of three contrasted GHG emission scenarios for the periods 2021-2050 and 2071-2100. Special attention was paid to the detection of both seasonal and spatial changes.

The results of the validation step show that the method reproduces some features of the observed current climate with good confidence, except for summer precipitation, which is underestimated. These deviations, which should not have significant impact on snowpack modelling, were nevertheless corrected statistically.

The methodology used here seems well suited to addressing the large topographic heterogeneities and generally sparse nature of the available observational dataset that characterize mountain regions. Detailed climate scenarios have been produced which force a complex snow model. The main conclusions drawn from an analysis of the results are as follows:

- Different GHG scenarios lead to marked differences in climate response for the 2071-2100 period, but earlier (2021-2050) for the snow response.

- Noticeable spatial differences in the magnitude of simulated changes in snowpack are detected. Snowpack in the Southern and Extreme Southern areas is clearly the most strongly affected by climate changes.

- The impact of climate change on snowpack is highly sensitive to altitudinal gradient, with significant SWE reduction at altitudes below 2000-2300 m a.s.l. in all massifs.

The question of the uncertainty has been assessed here in a preliminary manner by considering different emission scenarios. This analysis needs to be completed, ideally by considering every step in the modelling process that may introduce uncertainty: the emission scenario, as dealt with here, the global forcing from the GCM, the RCM and the resolution of its predictors, the adaptation method, and the snow model. Some of these aspects will be treated in a future study. Improvements of the method will involve consideration of more large-scale fields, which were not available from ALADIN but that will be obtained from other RCMs. Although the method seems to reproduce mean current climatological values satisfactorily, the adequate representation of temporal variability is not guaranteed. The limited number of parameters selected to compute the statistical distance (Z500, $\mathrm{T} 2 \mathrm{~m}$ and derived fields) are probably not suitable to represent the whole variety of weather phenomena. In particular, our method is not suited to addressing extreme climate events, which should therefore be treated with appropriate statistical tools (e.g. the extreme value theory, Coles, 2004).

Acknowledgements. We thank the scientific editor and two anonymous reviewers for their comments and suggestions which improved the manuscript greatly. We also acknowledge support by the SCAMPEI national project funded through grant ANR08-VULN-0009-01. This research was partially funded under the EU/FP7 project ACQWA (FP7-ENV-2007-1-212250).

Edited by: A. Nolin

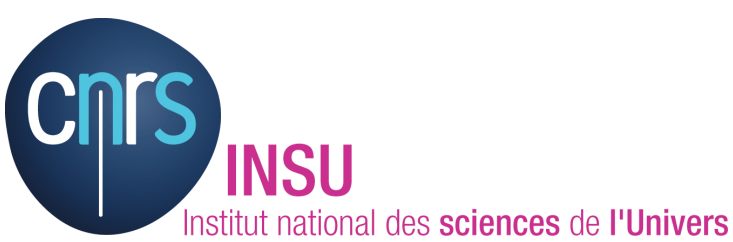

The publication of this article is financed by CNRS-INSU.

\section{References}

Acquaotta, F., Fratianni, S., Cassardo, C., and Cremonini, R.: On the continuity and climatic variability of the meteorological stations in Torino, Asti, Vercelli and Oropa, Meteor. Atm. Phys., 103, 279-287, 2009.

Alpert, P., Krichak, S. O., Shafir, H., Haim, D., and Osetinsky, I.: Climatic trends to extremes employing regional modeling and statistical interpretation over the $\mathrm{E}$. Mediterranean. Global Planet. Change, 63(2-3), 163-170, doi:10.1016/j.gloplacha.2008.03.003, 2008.

Beniston, M., Stoffel, M., and Hill, M.: Impacts of climatic change on water and natural hazards in the Alps: Can current water governance cope with future challenges? Examples from the European "ACQWA" project, Environ. Sci. Pol., doi:10.1016/j.envsci.2010.12.009, 2011.

Beniston, M.: Climatic change in mountain regions: A review of possible impacts, Theor. Appl. Climatol., 74, 19-31, doi:10.1007/s00704-002-0709-1, 2003.

Beniston, M., Keller, F. and Goyette, S.: Snow pack in the Swiss Alps under changing climatic conditions: an empirical approach for climate impacts studies, Climatic Change, 59, 5-31, 2003.

Beniston, M, Stoffel, M., and Hill, M.: Impacts of climatic change on water and natural hazards in the Alps: Can current water governance cope with future challenges? Examples from the European ACQWA project, Environ. Sci. Policy, doi:10.1016/j.envsci.2010.12.009, 2011.

Boé, J., Terray, L., Habets, F., and Martin, E.: Statistical and dynamical downscaling of the Seine basin climate for hydrometeorological Fstudies, Int. J. Climatol., 27, 1643-1655, doi:10.1002/joc.1602, 2007.

Boé, J., Terray, L., Martin, E., and Habets, F.: Projected changes in components of the hydrological cycle in French river basins during the 21st century, Water Resour. Res., 45, W08452, doi:10.1029/2008WR007437, 2009.

Brun, E., Martin, E., Simon, V., Gendre, C., and Coléou, C., An energy and mass model of snow cover suitable for operational avalanche forecasting, J. Glaciol., 35, 333-342, 1989.

Brun, E., David, P., Sudul, M., and Brugnot, G., A numerical model to simulate snow cover stratigraphy for operational avalanche forecasting, J. Glaciol., 38, 13-22, 1992.

Bubnová, R., Hello, G., Bénard, P., and Geleyn, J. F.: Integration of the fully elastic equations cast in the hydrostatic pressure terrain- 
following coordinate in the framework of ARPEGE/Aladin NWP system, Mon. Weather Rev., 123, 515-535, 1995.

Christensen, J. H. and Christensen, O. B.: A summary of the PRUDENCE model projections of changes in European climate by the end of this century, Clima. Change, 81, 7-30, doi:10.1007/s10584-006-9210-7, 2007.

Coles, S.: An Introduction to Statistical Modeling of Extreme Values, Third edition, Springer Series in Statistics, Springer-Verlag, London, UK, 2004.

Colin, J., Déqué, M., Radu, R., and Somot, S.: Sensitivity study of heavy precipitation in Limited Area Model climate simulations: influence of the size of the domain and the use of the spectral nudging technique, Tellus, 17, 591-604, doi:10.1111/j.16000870.2010.00467, 2010.

Déqué, M.: Frequency of precipitation and temperature extremes over France in an anthropogenic scenario: Model results and statistical correction according to observed values, Global Planet. Change, 57, 16-26, 2007.

Déqué, M. and Somot, S.: Added value of high resolution for ALADIN Regional Climate Model, Idöjaras Quaterly Journal of the Hungarian Meteorological Service, 112(3-4), 179-190, 2008.

Durand, Y., Brun, E., Mérindol, L., Guyomarch, G., Lesaffre, B., and Martin, E.: A meteorological estimation of relevant parameters for snow models, Ann. Glaciol., 18, 65-71, 1993.

Durand, Y., Giraud, G., Brun, E., Mérindol L., and Martin, E.: A computer-based system simulating snowpack structures as a tool for regional avalanche forecasting, J. Glaciol., 45, 469-484, 1999.

Durand, Y., Laternser, M., Giraud, G., Etchevers, P., Lesaffre, B., and Mérindol, L.: Reanalysis of 44 years of climate in the French Alps (1958-2002): Methodology, model validation, climatology and trends for air temperature and precipitation, J. Appl. Meteorol. Climatol., 48, 429-449, doi:10.1175/2008JAMC1808.1, 2009a.

Durand, Y., Giraud, G., Laternser, M., Etchevers, P., L. Mérindol, and Lesaffre, B.: Reanalysis of 47 years of climate in the French Alps (1958-2005): Climatology and trends for snow cover, J. Appl. Meteorol. Climatol., 48, 2487-2512, doi:10.1175/2009JAMC1810.1, 2009b.

ECMWF, ERA-40: ECMWF 45-years reanalysis of the global atmosphere and surface conditions 1957-2002, ECMWF Newsletter, 101 - Summer-Autumn 2004, Shinfield Park, Reading, Berkshire, RG29AX, UK, 2004.

Farda, A., Déqué, M., Somot, S., Horányi, A., Spiridonov, V., and Tóth, H.: Model Aladin as regional climate model for central and eastern Europe, Stud. Geophys. Geod., 54, 313-332, 2010.

Frei, C. and Schär, C.: A precipitation climatology of the Alps from high-resolution rain-gauge observations, Int. J. Climatol., 18, 873-900, doi:10.1002/joc255, 1998.

Frey-Buness, F., Heimann, D., and Sausen, R.: A statisticaldynamical downscaling procedure for global climate simulations, Theoret. Appl. Climatol., 50, 117-131, 1995.

Gibelin, A. L. and Déqué, M.: Anthropogenic climate change over the Mediterranean region simulated by a global variable resolution model, Clim. Dynam., 20, 327-339, 2003.

Hagemann, S., Machenhauer, B., Jones, R., Christensen, O. B., Déqué, M., Jacob, D., and Vidale, P. L.: Evaluation of water and energy budgets in regional climate models applied over Europe, Clim. Dynam., 23, 547-567, 2004.
Hantel, M., Ehrendorfer, M., and Haslinger, A.: Climate sensitivity of snow cover duration in Austria, Int. J. Climatol., 20, 615-640, doi:10.1002/joc489, 2000.

Hewitt, C.D., and Griggs, D.J.: Ensembles-based predictions of climate changes and their impacts, EOS, 85, 566, 2004.

Hohenegger, C., Brockhaus, P., and Schär, C.: Towards climate simulations at cloud-resolving scales., Meteorol. Zeitschrift, 17, 383-394, doi:10.1127/0941-2948/2008/0303, 2008.

IPCC: Climate change 2007: The physical science basis, in: Contribution of working group I to the fourth assessment report of the Intergovernmental Panel on Climate Change, edited by: Solomon, S., Qin, D., Manning, M., Chen, Z., Marquis, M., Averyt, K. B., Tignor, M., and Miller H. L., Cambridge University Press, Cambridge, UK and New York, NY, USA, 2007.

Kallache, M., Vrac, M., Naveau, P., and Michelangeli P.-A.: Nonstationary probabilistic downscaling of extreme precipitation, J. Geophys. Res., 116, D05113, doi:10.1029/2010JD014892, 2011.

Kettle, H., and Thompson, R., Statistical downscaling in European mountains: verification of air temperature reconstructions, Climate Res., 26(2), 97-112, 2004.

Laternser, M. and Schneebeli, M.: Long-term snow climate trends of the Swiss Alps (1931-99), Int. J. Climatol., 23, 733-750, doi:10.1002/joc.912, 2003.

van der Linden, P. and Mitchell, J. F. B., ENSEMBLES: Climate Change and its Impacts: Summary of research and results from the ENSEMBLES project, Tech. rep., Met Office Hadley Centre, FitzRoy Road, Exeter EX1 3PB, UK, 2009.

López-Moreno, J. I., Goyette, S., and Beniston, M.: Impact of climate change on snowpack in the Pyrenees: horizontal and spatial variability and vertical gradients, J. Hydrol., 374, 384-396, doi:10.1016/j.jhydrol.2009.06.049, 2009.

Mahalanobis, P.C.: On the generalised distance in statistics, Proceedings of the National Institute of Sciences of India, 2, 49-55, 1936.

Maraun, D., Wetterhall, F., Ireson, A. M., Chandler, R. E. , Kendon, E. J., Widmann, M., Brienen, S., Rust, H. W., Sauter, R., Theme, M., Venema, V. K. C., Chun, K. P., Goodess, C. M., Jones, R. G., Onof, C., Vrac, M., and Thiele-Eich I.: Precipitation downscaling under climate change: recent developments to bridge the gap between dynamical models and the end user. Rev. Geophys., 48, RG3003, doi:10.1029/2009RG000314, 2010b.

Martin, E. and Etchevers P.: Impact of climatic changes on snow cover and snow hydrology in the French Alps. Adv. Glob. Change Res., 23, 235-242, doi:10.1007/1-4020-3508X_24, 2005.

Martin, E., Brun, E., and Durand, Y.: Sensitivity of the French Alps snow cover to the variation of climatic variables, Ann. Geophys., 12, 469-477, doi:10.1007/s00585-994-0469-6, 1994.

Martin, E., Timbal, B., and Brun, E.: Downscaling of general circulation model outputs: simulation of the snow climatology of the French Alps and sensitivity to climate change, Clim. Dynam., 13, 45-56, 1997.

Radu, R., Déqué, M., and Somot, S.: Spectral nudging in a spectral regional climate model. Tellus, 60A, 885-897, 2008.

Schmidli, J., Goodess, C. M., Frei, C., Haylock, M. R., Hundecha, Y., Ribalaygua, J., and Schmith, T.: Statistical and dynamical downscaling of precipitation: An evaluation and comparison of scenarios for the European Alps, J. Geophys. Res., 112, D04105, doi:10.1029/2005JD007026, 2007. 
Schöner, W., Auer, I., and Böhm R.: Climate variability and glacier reaction in the Austrian eastern Alps, Ann. Glaciol., 31, 31-38, 2000 .

Terray, L., Demory, M. E., Déqué, M. , de Coetlogon, G., and Maisonnave, E.: Simulation of late twenty-first century changes in wintertime atmospheric circulation over Europe due to anthropogenic causes, J. Climate, 17, 4630-4635, 2004. 